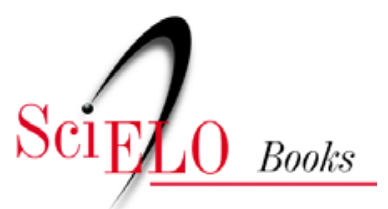

\title{
4 - Dinâmica dos investimentos no subsistema de base mecânica, eletrônica e de materiais
}

\author{
Carlos A. Grabois Gadelha (cood.)
}

\section{SciELO Books / SciELO Livros / SciELO Libros}

GADELHA, CAG., cood. Dinâmica dos investimentos no subsistema de base mecânica, eletrônica e de materiais. In: A dinâmica do sistema produtivo da saúde: inovação e complexo econômicoindustrial [online]. Rio de Janeiro: Editora FIOCRUZ, 2012, pp. 105-142. ISBN: 978-85-7541-593-1. Available from: doi: $10.7476 / 9788575415931.0005$. Also available in ePUB from: http://books.scielo.org/id/6t3hs/epub/gadelha-9788575415931.epub

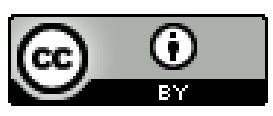

All the contents of this work, except where otherwise noted, is licensed under a Creative Commons Attribution 4.0 International license.

Todo o conteúdo deste trabalho, exceto quando houver ressalva, é publicado sob a licença Creative Commons Atribição 4.0. 


\section{4 \\ Dinâmica dos Investimentos no Subsistema de Base Mecânica, Eletrônica e de Materiais}

Este subsistema congrega um conjunto bastante díspar de atividades de base física, mecânica, eletrônica e de materiais, que envolve as indústrias de equipamentos e instrumentos mecânicos e eletrônicos, órteses e próteses e materiais de consumo em geral. As atividades nele desenvolvidas estão fortemente associadas às práticas médicas, o que muitas vezes determina a tecnologia incorporada nos procedimentos de prevenção, diagnóstico e tratamento de doenças adotados. Incorporam, de fato, segmentos bastante diversificados, que abrangem desde bens de capital de alta complexidade (como equipamento para diagnóstico por imagem) até materiais de consumo de uso rotineiro, passando por instrumentos, material cirúrgico e ambulatorial, seringas, entre muitos outros exemplos.

Neste segmento produtivo, cabe destacar o papel da indústria de equipamentos, tanto por seu potencial de inovação - incorpora fortemente os avanços associados ao paradigma microeletrônico - quanto pelo impacto que exerce sobre os serviços, por representar uma fonte constante de mudanças nas práticas assistenciais, trazendo permanentemente para o debate a tensão entre a lógica da indústria e a sanitária.

A indústria de equipamentos e materiais se caracteriza, então, por significativa heterogeneidade tecnológica, o que tem gerado grande diversidade e heterogeneidade de classificações internacionais. O North American Industrial Classification System (NAICS), por exemplo, inclui entre os equipamentos médicos desde equipamentos eletromédicos, aparelhos de radiação (raios X), instrumentos médicos e cirúrgicos e equipamentos odontológicos até material de consumo médico e cirúrgico e produtos oftálmicos (Furtado \& Souza, 2001; Exportmed Brazil, 2004). A União Europeia (UE), de acordo com o European Union Medical Devices Directive (artigo 1), considera como equipamento médico qualquer instrumento, aparato, dispositivo, material ou outro artigo, usado tanto individualmente como em combinação, incluindo o software necessário para sua adequada aplicação, a ser usado em seres humanos 
com o propósito de diagnóstico, tratamento, prevenção ou monitoramento para fins diversos (Pammolli et al., 2005).

No Brasil, a Associação Brasileira da Indústria de Artigos e Equipamentos Médicos, Odontológicos, Hospitalares e de Laboratórios (Abimo) adota uma classificação baseada nos mercados atendidos, nas seguintes categorias: odontologia, laboratório, radiologia, equipamentos médico-hospitalares, implantes e material de consumo. Tal classificação significa que mais de 11.000 famílias de produtos são incluídas na qualidade de equipamentos médico-hospitalares e odontológicos (Abimo, 2008).

O Instituto Brasileiro de Geografia e Estatística (IBGE), de acordo com o Cadastro Nacional de Atividades Econômicas (CNAE), inclui como aparelhos e instrumentos para uso médico hospitalar e odontológico os apresentados no Quadro 8.

Quadro 8 - Aparelhos e instrumentos para uso médico-hospitalar. Classificação IBGE

\begin{tabular}{|c|l|}
\hline \multicolumn{2}{|c|}{ CNAE 2.0 } \\
\hline $32507 / 01$ & $\begin{array}{l}\text { Instrumentos não eletrônicos e utensílios para uso médico, cirúrgico, odontológico e de } \\
\text { laboratório }\end{array}$ \\
\hline $32507 / 02$ & Mobiliário para uso médico, cirúrgico, odontológico e de laboratório \\
\hline $32507 / 03$ & $\begin{array}{l}\text { Aparelhos e utensílios para correção de defeitos físicos e aparelhos ortopédicos em geral sob } \\
\text { encomenda }\end{array}$ \\
\hline $32507 / 04$ & $\begin{array}{l}\text { Aparelhos e utensílios para correção de defeitos físicos e aparelhos ortopédicos em geral, } \\
\text { exceto sob encomenda }\end{array}$ \\
\hline $32507 / 05$ & Materiais para medicina e odontologia \\
\hline $32507 / 06$ & Próteses dentárias \\
\hline $32507 / 07$ & Artigos ópticos \\
\hline $32507 / 08$ & Artefatos de tecido não tecido para uso odonto-médico-hospitalar \\
\hline
\end{tabular}

Fonte: PIA/IBGE, 2012b.

Por sua vez, a Pesquisa Industrial de Inovação Tecnológica (Pintec/IBGE) agrega as informações relativas à indústria, juntamente com a fabricação de instrumentos de precisão e óticos, equipamentos para automação industrial, cronômetros e relógios.

Essa imensa diversidade de tecnologias, produtos e mercados da indústria - e, portanto, a falta de harmonização das classificações utilizadas, tanto em nível global como nacional - dificulta uma análise das informações em bases comparativas. Todavia, isso não impede o entendimento, em um nível mais abrangente, da dinâmica sistêmica, mediante uma abordagem que combina o recorte tecnológico e de mercado, focalizada nos segmentos mais intensivos em inovação, como os equipamentos e instrumentos médico-hospitalares eletrônicos e 
mecânicos (e, cada vez mais, mecatrônicos) e os novos materiais que caracterizam a base tecnológica deste subsistema. ${ }^{17}$

\section{DINÂMICA GLOBAL DO INVESTIMENTO}

As indústrias deste subsistema, em geral, podem ser caracterizadas como oligopólios baseados na diferenciação de produtos e no fornecimento de bens altamente especializados, com grande quantidade de novos produtos sendo lançados continuamente, novas opções de tratamento e diagnóstico, ciclos tecnológicos curtos (com duração de menos de dois anos) e comercializados em associação com serviços e outros produtos (Leão, Oliveira \& Albornoz, 2008). A diferenciação de produtos se baseia na intensidade dos gastos em Pesquisa e Desenvolvimento (P\&D), e a natureza dos conhecimentos que incorporam assenta-se fortemente nas ciências físicas de base mecânica e eletrônica e em avanços tecnológicos oriundos de outras indústrias tradicionalmente inovadoras, a exemplo da microeletrônica, mecânica de precisão, química e novos materiais (Gadelha, 2007).

Uma característica marcante da relação deste subsistema no âmbito do Complexo Econômico-Industrial da Saúde (CEIS) é o fato de o processo de difusão tecnológica ser extremamente rápido nos serviços de saúde; além disso, normalmente as tecnologias da área não são substitutivas, e sim complementares e cumulativas, o que inclusive pressiona os custos decorrentes da prestação de serviços de saúde (Castro, 2003). Mais relevante do que o esforço por eficiência produtiva, verificase uma pressão permanente para a adição de novos procedimentos, a exemplo da utilização de ressonância magnética, da tomografia computadorizada, da ultrassonografia e dos raios X muitas vezes nas mesmas unidades prestadoras de serviços de diagnóstico por imagem.

A Tabela 18 apresenta as dez empresas que mais investiram em P\&D na indústria em 2009, especificando para cada uma o montante investido, o crescimento percentual dos últimos três anos, o percentual sobre vendas e o crescimento percentual médio das vendas nos três anos; nela se pode constatar com clareza a liderança de empresas norte-americanas.

Em um ambiente cada vez mais competitivo, as empresas desenvolvem, além da atividade formal de $P \& D$, outras estratégias de apropriação externa de conhecimento, seja na forma de acordos de colaboração, seja em processos interativos com outros agentes socioeconômicos. Essas estratégias têm caracterizado a dinâmica industrial de modo intensivo e crescente desde a década de 1990, sob a forma de fusões e

${ }^{17}$ As considerações gerais, a menos que sejam especificadas, sempre procuram captar a dinâmica destes segmentos mais intensivos em inovação, sejam apresentados como "a indústria de equipamentos", de "equipamentos ou materiais" ou do "subsistema", muitas vezes não se aplicando aos segmentos menos densos em conhecimento. 
aquisições, alianças (joint ventures, acordos de P\&D, acordos de marketing) e acordos de financiamento (Pammolli et al., 2005).

Tabela 18 - Empresas que mais investiram em P\&D na indústria, 2009

\begin{tabular}{l|c|c|c|c|c}
\hline EMPRESA & PAÍS & $\begin{array}{c}\text { INVESTIMENTOS P\&D } \\
(€ \text { MILHÖES })\end{array}$ & $\begin{array}{c}\text { \% CRESCIMENTO DO } \\
\text { INVESTIMENTO EM P\&D } \\
\text { NOS ÚLTIMOS 3 ANOS }\end{array}$ & $\begin{array}{c}\text { INVESTIMENTO EM } \\
\text { P\&D COMO \% DAS } \\
\text { VENDAS }\end{array}$ & $\begin{array}{c}\text { \% CRESCIMENTO } \\
\text { DE VENDAS NOS } \\
\text { ÚLIIMOS 3 ANOS }\end{array}$ \\
\hline Meditronic & EUA & $1.124,10$ & 5,8 & 9,5 & 5,6 \\
\hline Boston Scientific & EUA & 699,95 & $-4,9$ & 12 & $-2,2$ \\
\hline Baxter International & EUA & 682,1 & 3,7 & 7 & -6 \\
\hline Olympus & Japão & 568,5 & 58 & 13,1 & 51 \\
\hline Saint Jude Medical & EUA & 470,4 & 9,8 & 12,2 & 11 \\
\hline Becton & EUA & 392,2 & 13,5 & 7 & 5,7 \\
\hline Stryker & EUA & 293,62 & 1,6 & 5,4 & 6,9 \\
\hline Thermo Fischer Scientific & EUA & 214,1 & 6,4 & 2,7 & 3,4 \\
\hline Beckman Coulter & EUA & 200,2 & $-0,7$ & 7,3 & 9,9 \\
\hline Zimmer & EUA & 170 & 1,6 & 5,2 & 2,7 \\
\hline
\end{tabular}

Fonte: elaboração própria (GIS/Ensp/Fiocruz), com base nos dados de R\&D Scoreboard, 2010.

Apesar da grande intensidade de P\&D que caracteriza a indústria, em alguns segmentos de menor complexidade tecnológica, como o mercado de seringas, luvas e equipamentos de diagnóstico mais convencionais, o padrão de competição se baseia em preços, a produção e os ganhos de competitividade estão vinculados à escala e as margens de lucro são mais reduzidas (Leão, Oliveira \& Albornoz, 2008).

De acordo com Gutierrez e Alexandre (2004), a indústria de equipamentos e materiais médico-hospitalares e odontológicos tem apresentado um dinamismo significativo nos últimos anos, decorrente de: incorporação de avanços tecnológicos, que tem significado o constante desenvolvimento de novos produtos com novas funções; envelhecimento da população, sobretudo nos países desenvolvidos, que tem promovido a ampliação da demanda por serviços de saúde; crescimento do mercado, sobretudo dos países em desenvolvimento, essencialmente no que tange à reformulação dos sistemas de saúde e aumentos dos gastos em saúde.

O desenvolvimento de novas tecnologias e novos tratamentos cada vez mais aperfeiçoados e mais caros; o caráter cumulativo da utilização das tecnologias, que significa uso de maior número de equipamentos e o concomitante aumento dos custos de manutenção; e a ampliação dos serviços de saúde têm, em conjunto, significado o aumento dos gastos com serviços de saúde. Assim, mesmo que nos segmentos 
mais dinâmicos predomine a estratégia de diferenciação de produtos, tal contexto, por significar crescente pressão pelo controle dos gastos públicos e privados com a saúde em nível mundial, acirrada pela crescente demanda por serviços de saúde, tem pressionado as empresas a também concentrarem parte de seus esforços tecnológicos na redução dos custos dos tratamentos.

O faturamento do mercado mundial de equipamentos e materiais em 2009

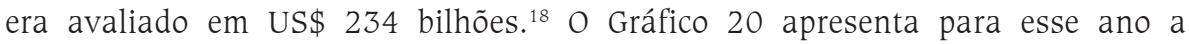
distribuição desse mercado por região. A Tabela 19, por sua vez, apresenta para 2009 a participação do faturamento proveniente de equipamentos e materiais no mercado mundial, em valor e percentual, por principais países, constatando-se a forte concentração da indústria nos países da tríade EUA, Japão e quatro países da Europa Ocidental. ${ }^{19}$ Os Estados Unidos da América (EUA) representam de forma inconteste o maior mercado mundial, com praticamente $40 \%$ do total, e em conjunto com Japão, Alemanha, França, Itália e Grã-Bretanha respondem por quase $70 \%$ do total mundial. Os designados Brics - Brasil, Rússia, Índia e China -, embora individualmente participem de forma reduzida, em conjunto representam $6,8 \%$ do total. Esse padrão de distribuição internacional da produção e do mercado também se confirma quando se analisam os dados de comércio exterior (Tabelas 20 e 21), havendo um elevado dinamismo nas importações e exportações no período recente (The World Medical Fact Book, 2010).

Gráfico 20 - Equipamentos e materiais: distribuição percentual do mercado mundial por região - 2009

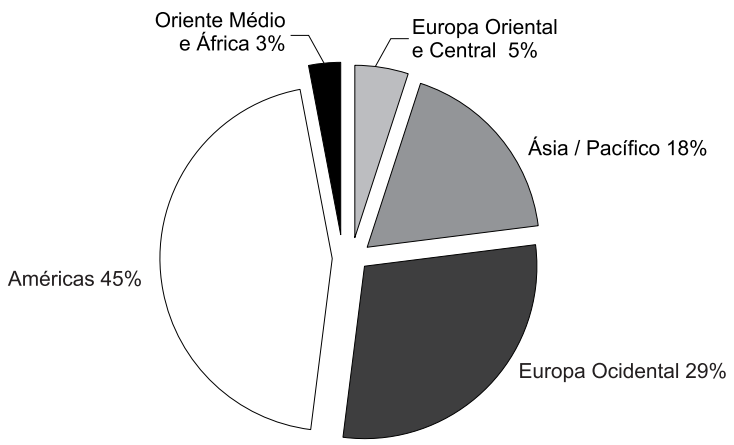

Fonte: The World Medical Markets Fact Book, 2010.

\footnotetext{
${ }^{18}$ A distribuição percentual da composição do mercado mundial por tipo de produto em 2009 é a seguinte: material de consumo, 17\%; diagnóstico por imagem, 24\%; ortopédico, 17\%; odontológico, 6\%; outros equipamentos, 36\% (The World Medical Markets Fact Book, 2010).

${ }^{19}$ As vinte maiores empresas controlam 70\% da produção mundial (ABDI, 2009).
} 
Tabela 19 - Participação no mercado mundial por principais países - 2009

\begin{tabular}{|c|c|c|c|}
\hline & PAÍS & US\$ MILHÕES & $\%$ \\
\hline 1 & Estados Unidos & $92.662,20$ & $39,7 \%$ \\
\hline 2 & Japão & $21.712,80$ & $9,3 \%$ \\
\hline 3 & Alemanha & 18.843 & $8,1 \%$ \\
\hline 4 & França & 9.071 & $3,9 \%$ \\
\hline 5 & Itália & 8.703 & $3,7 \%$ \\
\hline 6 & Grã-Bretanha & 8.284 & $3,5 \%$ \\
\hline 7 & China & $6.694,60$ & $2,9 \%$ \\
\hline 8 & Canadá & $4.922,10$ & $2,1 \%$ \\
\hline 9 & Rússia & 4.913 & $2,1 \%$ \\
\hline 10 & Espanha & $4.257,20$ & $1,8 \%$ \\
\hline 11 & Suíça & $3.968,80$ & $1,7 \%$ \\
\hline 12 & Austrália & $3.369,60$ & $1,4 \%$ \\
\hline 13 & Coreia do Sul & $3.034,90$ & $1,3 \%$ \\
\hline 14 & México & $2.607,60$ & $1,1 \%$ \\
\hline 15 & Holanda & 2.371 & $1,0 \%$ \\
\hline 16 & Áustria & 2.222 & $1,0 \%$ \\
\hline 17 & BRASIL & $2.219,10$ & $0,9 \%$ \\
\hline 18 & Suécia & $2.194,60$ & $0,9 \%$ \\
\hline 19 & Índia & $1.986,20$ & $0,9 \%$ \\
\hline 20 & Dinamarca & $1.890,50$ & $0,8 \%$ \\
\hline \multirow[t]{2}{*}{21} & Outros & $27.723,70$ & $11,9 \%$ \\
\hline & Total & $233.650,90$ & $100 \%$ \\
\hline
\end{tabular}

Fonte: The World Medical Markets Fact Book, 2010. 
Tabela 20 - Ranking das importações mundiais em valor e percentual por principais países

\begin{tabular}{|c|c|c|c|c|c|c|c|}
\hline & \multirow{2}{*}{ PAÍS } & \multicolumn{2}{|c|}{2004} & \multicolumn{2}{|c|}{2007} & \multicolumn{2}{|c|}{2009} \\
\hline & & $U S \$ B I$ & $\%$ & $U S \$ B I$ & $\%$ & US\$BI & $\%$ \\
\hline 1 & EUA & 21.267 & $21,2 \%$ & 27.450 & $19,2 \%$ & 30.073 & $19,0 \%$ \\
\hline 2 & Alemanha & 8.530 & $8,5 \%$ & 12.997 & $9,1 \%$ & 14.607 & $9,2 \%$ \\
\hline 3 & Holanda & 6.468 & $6,4 \%$ & 9.353 & $6,5 \%$ & 10.410 & $6,6 \%$ \\
\hline 4 & França & 6.712 & $6,7 \%$ & 8.969 & $6,3 \%$ & 10.126 & $6,4 \%$ \\
\hline 5 & Japão & 7.188 & $7,2 \%$ & 8.243 & $5,8 \%$ & 9.532 & $6,0 \%$ \\
\hline 6 & Bélgica & 3.396 & $3,4 \%$ & 5.681 & $4,0 \%$ & 7.552 & $4,8 \%$ \\
\hline 7 & Grã-Bretanha & 6.154 & $6,1 \%$ & 7.874 & $5,5 \%$ & 7.303 & $4,6 \%$ \\
\hline 8 & Itália & 4.390 & $4,4 \%$ & 5.763 & $4,0 \%$ & 6.162 & $3,9 \%$ \\
\hline 9 & China & 2.647 & $2,6 \%$ & 3.586 & $2,5 \%$ & 4.982 & $3,1 \%$ \\
\hline 10 & Canadá & 2.861 & $2,9 \%$ & 4.079 & $2,9 \%$ & 4.318 & $2,7 \%$ \\
\hline 12 & Rússia & 1.131 & $1,1 \%$ & 3.382 & $2,4 \%$ & 3.754 & $2,4 \%$ \\
\hline 21 & Brasil & 651 & $0,6 \%$ & 1.411 & $1,0 \%$ & 1.685 & $1,1 \%$ \\
\hline \multirow[t]{3}{*}{23} & Índia & 690 & $0,7 \%$ & 1.302 & $0,9 \%$ & 1.545 & $1,0 \%$ \\
\hline & Outros & 28.207 & $28,1 \%$ & 42.914 & $30,0 \%$ & 46.130 & $29,2 \%$ \\
\hline & Total & 100.293 & $100 \%$ & 143.005 & $100 \%$ & 158.181 & $100 \%$ \\
\hline
\end{tabular}

Fonte: The World Medical Markets Fact Book, 2010.

Tabela 21 - Ranking das exportações mundiais em valor e percentual por principais países

\begin{tabular}{c|l|c|c|c|c|c|c}
\hline \multirow{2}{*}{\multicolumn{2}{c|}{ PAís }} & \multicolumn{2}{c|}{2004} & \multicolumn{2}{c|}{2007} & \multicolumn{2}{c}{2009} \\
\cline { 3 - 8 } \multicolumn{2}{l|}{} & US\$BI & $\%$ & US\$BI & $\%$ & US\$BI & $\%$ \\
\hline 1 & EUA & 21.842 & $21,5 \%$ & 30.896 & $21,7 \%$ & 35.705 & $22,7 \%$ \\
\hline 2 & Alemanha & 14.027 & $13,8 \%$ & 21.350 & $15,0 \%$ & 22.507 & $14,3 \%$ \\
\hline 3 & Holanda & 8.075 & $8,0 \%$ & 11.459 & $8,1 \%$ & 11.328 & $7,2 \%$ \\
\hline 4 & França & 5.976 & $5,9 \%$ & 8.053 & $5,7 \%$ & 9.099 & $5,8 \%$ \\
\hline 5 & Irlanda & 7.849 & $7,7 \%$ & 6.826 & $4,8 \%$ & 8.980 & $5,7 \%$ \\
\hline 6 & Suíça & 5.003 & $4,9 \%$ & 7.285 & $5,1 \%$ & 8.913 & $5,7 \%$ \\
\hline 7 & Bélgica & 3.766 & $3,7 \%$ & 5.741 & $4,0 \%$ & 8.612 & $5,5 \%$ \\
\hline 8 & China & 2.418 & $2,4 \%$ & 5.354 & $3,8 \%$ & 7.085 & $4,5 \%$ \\
\hline
\end{tabular}


Tabela 21 - Ranking das exportações mundiais em valor e percentual por principais países (continuação)

\begin{tabular}{|c|c|c|c|c|c|c|c|}
\hline & \multirow{2}{*}{ PAís } & \multicolumn{2}{|c|}{2004} & \multicolumn{2}{|c|}{2007} & \multicolumn{2}{|c|}{2009} \\
\hline & & $U S \$ B I$ & $\%$ & US\$ BI & $\%$ & $U S \$ B I$ & $\%$ \\
\hline 9 & Grã-Bretanha & 5.397 & $5,3 \%$ & 7.197 & $5,1 \%$ & 6.058 & $3,8 \%$ \\
\hline 10 & Japão & 4.867 & $4,8 \%$ & 5.632 & $4,0 \%$ & 5.445 & $3,5 \%$ \\
\hline 28 & Brasil & 239 & $0,2 \%$ & 442 & $0,3 \%$ & 516 & $0,3 \%$ \\
\hline 29 & Índia & 342 & $0,3 \%$ & 493 & $0,3 \%$ & 450 & $0,3 \%$ \\
\hline \multirow[t]{3}{*}{45} & Rússia & 65 & $0,1 \%$ & 111 & $0,1 \%$ & 95 & $0,1 \%$ \\
\hline & Outros & 21.510 & $21,2 \%$ & 31.322 & $22,0 \%$ & 32.795 & $20,8 \%$ \\
\hline & Total & 101.374 & $100 \%$ & 142.161 & $100 \%$ & 157.588 & $100 \%$ \\
\hline
\end{tabular}

Fonte: The World Medical Markets Fact Book, 2010.

A Tabela 22 apresenta os vinte maiores fabricantes mundiais da indústria de equipamentos e materiais médico-hospitalares e odontológicos, seus respectivos países de origem e seu faturamento em 2011.

Tabela 22 - Maiores empresas da indústria - 2011

\begin{tabular}{c|l|c|c}
\hline RANKING & \multicolumn{1}{|c|}{ EMPRESA } & PAíS & RECEITA (EM US\$ BILHÕES) \\
\hline 1 & Johnson \& Johnson & EUA & 23.6 \\
\hline 2 & Siemens Healthcare & Alemanha & 17.4 \\
\hline 3 & GE & EUA & 16.0 \\
\hline 4 & Medtronic & EUA & 14.6 \\
\hline 5 & Baxter International & EUA & 12.6 \\
\hline 6 & Phillips Healthcare & EUA & 11.2 \\
\hline 7 & Abbott Laboratories & EUA & 8.4 \\
\hline 8 & Boston Scientific & EUA & 8.2 \\
\hline 9 & Covidien (antiga Tyco Healthcare) & Irlanda / EUA & 7.8 \\
\hline 10 & Becton Dickinson & EUA & 7.2 \\
\hline 11 & Stryker & EUA & 6.7 \\
\hline 12 & B. Braun & Alemanha & 5.8 \\
\hline 13 & St. Jude Medical & EUA & 4.7 \\
\hline 14 & Cardinal Health & EUA & 4.6 \\
\hline
\end{tabular}


Tabela 22 - Maiores empresas da indústria - 2011 (continuação)

\begin{tabular}{c|l|c|c}
\hline RANKING & EMPRESA & PAís & RECEITA (EM US\$ BLLHÕES) \\
\hline 15 & 3 M Healthcare & EUA & 4.3 \\
\hline 16 & Zimmer & EUA & 4.1 \\
\hline 17 & Olympus Medical & Japão & 4.0 \\
\hline 18 & Hospira & EUA & 3.9 \\
\hline 19 & Smith \& Nephew & Reino Unido & 3.8 \\
\hline 20 & Toshiba & Japão & 3.7 \\
\hline
\end{tabular}

Fonte: elaboração própria (GIS/Ensp/Fiocruz), com base em dados da PHC Consulting, 2011.

Verifica-se a forte presença norte-americana, com 15 empresas, na relação das vinte maiores empresas da indústria. De acordo com Leão, Oliveira e Albornoz (2008), o sucesso das empresas norte-americanas nesta indústria é resultado da convergência de um conjunto de fatores: o ambiente institucional e empresarial no qual as empresas estão inseridas; a extensão do mercado privado dos serviços de saúde, com ampla capacidade de absorção de uma oferta crescente de novos produtos; a forte atuação do governo na abertura de novos mercados e no acesso a estes; o tradicional engajamento das empresas em P\&D. Complementarmente, a existência de indústrias correlatas nos EUA - a exemplo das de microeletrônica, telecomunicações, instrumentação, biotecnologia, desenvolvimento de software, entre outras - reforça a posição competitiva das empresas norte-americanas nesta indústria (Selan, Porto \& Kannebley Júnior, 2007).

A dimensão do mercado nacional, a forte participação no comércio exterior e o porte das empresas fazem dos EUA o grande player da indústria. Com cadeias produtivas em todos os segmentos, os investimentos norte-americanos no exterior visam a ampliar suas participações nos principais mercados consumidores (sobretudo Europa e Japão), ao passo que o principal critério locacional dos investimentos europeus e japoneses em relação ao mercado norte-americano é a proximidade com o polo mundial dominante da indústria. Por não terem a mesma capacidade tecnológica e industrial, os demais países concorrentes, especialmente os europeus e o Japão, desenvolvem estratégias de especialização e de segmentação. A Alemanha, por exemplo, procurou se especializar no segmento de diagnóstico por imagem, em que a principal empresa é a Siemens, e no de implantes. O Japão, por sua vez, se destaca principalmente em aparelhos de ultrassonografia, de eletrodiagnóstico e em instrumentos oftálmicos. Toshiba Medical, Shimadzu e Hitachi se destacam como as grandes empresas japonesas, detendo, em conjunto, 70\% do mercado japonês (Selan, Porto \& Kannebley Júnior, 2007). 
A liderança do mercado mundial é exercida, indubitavelmente, por grandes empresas, que estabelecem o padrão e o ritmo de incorporação tecnológica da indústria e têm, cada vez mais, adotado estratégias de integração de suas atividades comerciais e industriais em nível global. No âmbito das aquisições e fusões, além de racionalizar custos, as adquirentes ganham acesso instantâneo a novos produtos, a novos clientes e a uma infraestrutura de vendas e de assistência técnica, e ampliam seu poder de negociação com os compradores. Nos últimos anos, o processo de aquisições e fusões na indústria tem sido intenso. Apenas nos dez primeiros meses de 2010 foram registradas 262 transações de fusão ou joint ventures - 228 concretizadas e 34 anunciadas (MDDI Online, 2010). A Tabela 23 apresenta as dez maiores transações realizadas em 2011.

Entre os motivos desse movimento de concentração na indústria, salientam-se a existência de inúmeras pequenas empresas tecnologicamente muito dinâmicas que, todavia, não dispõem de recursos complementares para o processo de difusão de seus desenvolvimentos e acabam atraindo a atenção das grandes empresas; e o envelhecimento da população, que tem pressionado a demanda por serviços de saúde e, concomitantemente, por equipamentos médicos.

Tabela 23 - Principais aquisições na indústria de equipamentos e materiais médico-hospitalares e odontológicos - 2011

\begin{tabular}{c|c|c}
\hline $\begin{array}{c}\text { VALOR DA TRANSACÃO } \\
\text { (US\$ MLHÖES) }\end{array}$ & EMPRESA ADQUIRENTE & EMPRESA ADQUIRIDA \\
\hline $10.567,1$ & Novartis AG & Alcon Inc. \\
\hline $7.200,0$ & Merck KGaA & Millipore Corp. \\
\hline $2.490,0$ & Covidien PLC & ev3 Inc. \\
\hline $1.080,0$ & St. Jude Medical Inc. & AGA Medical Holdings \\
\hline 580,0 & GE Healthcare & Clarient Inc. \\
\hline 387,5 & Johnson \& Johnson & Micrus Endovascular Corp. \\
\hline 350,9 & BioScrip Inc. & Critical Homecare Solutions Holding Inc. \\
\hline 350,0 & Medtronic Inc. & Invatec SpA \\
\hline 317,7 & Medtronic Inc. & ATS Medical Inc. \\
\hline 291,9 & Covidien PLC & Somanetics Corp. \\
\hline
\end{tabular}

Fonte: elaboração própria (GIS/Ensp/Fiocruz), com base nos dados de MDDI Online, 2010.

Deve-se salientar o crescente interesse das empresas farmacêuticas por esta indústria. Diante dos desafios atuais da indústria farmacêutica - baixa produtividade da $P \& D$, expiração de patentes, perda de dinamismo das designadas economias farmacêuticas maduras, entre outros aspectos -, as empresas têm adotado estratégias de diversificação de seus investimentos. Essa convergência entre farmacêutica e 
equipamentos pode ser ilustrada pelas aquisições da Animas Corporation pela Johnson \& Johnson; da American Medical Instrument Co e da Quill Medical pela Angiotech Pharmaceuticals Inc; pelo anúncio da Merck sobre uma aquisição de participação societária na Foxhollow (Burkhardt \& Tardio, 2006); e pela diversificação da Roche para a área de equipamentos para diagnóstico (The Guardian, 2008).

Ainda do ponto de vista da internacionalização da produção, assiste-se ao crescente interesse, por parte das multinacionais, nos mercados emergentes, em função de suas taxas de crescimento, da ampliação de seus sistemas nacionais de saúde, da extensão da cobertura das redes de assistência e da expansão dos gastos públicos em saúde. Nesses mercados emergentes, os Brics têm papel de destaque: em 2010, o conjunto de dispêndios em saúde desses países foi superior ao da Alemanha em mais de US\$ 270 bilhões (World Bank, 2012). Em que pesem suas diferenças relativas, os quatros países, na visão de investidores externos, apresentam os seguintes pontos positivos em comum: população urbanizada com crescente poder de compra; dinamismo econômico e perspectivas de crescimento; indústria local de intensidade tecnológica baixa e média; dependência de importaçôes, sobretudo de itens de maior complexidade tecnológica (Selan, Porto \& Kannebley, 2007).

Relativamente ao perfil empresarial, as grandes empresas predominam nos segmentos cujos produtos apresentam maior complexidade tecnológica e maior valor agregado. Contudo, verifica-se também a forte presença de pequenas e médias empresas em atividades especializadas e segmentadas (Gutierrez \& Alexandre, 2004). Assim, no âmbito da política de desenvolvimento industrial e de inovação, mostramse factíveis a entrada de países menos desenvolvidos em certos nichos de mercado e a concepção de estratégias empresariais e nacionais de desenvolvimento focalizadas nesses segmentos, sejam de máquinas, instrumentos ou bens de consumo de menor complexidade (Gadelha, 2007).

\section{TENDÊNCIAS DOS INVESTIMENTOS NO BRASIL}

No Brasil, a indústria de equipamentos e materiais se estruturou entre as décadas de 1950 e 1980 no esteio do modelo de substituição de importações, tendo progressivamente passado a ofertar instrumentos médicos, materiais de consumo e equipamentos eletrônicos de maior densidade tecnológica.

Contudo, a década de 1990 foi marcada por transformações estruturais no funcionamento dessa indústria, em decorrência do processo de abertura comercial, o que significou uma crescente dependência do país em relação às importações de equipamentos, sobretudo, de maior densidade tecnológica. Diante da falta de competitividade em relação às multinacionais, uma série de produtos que havia sido incorporada à produção local nas décadas anteriores deixa de ser produzida no país, como, por exemplo, marca-passos implantáveis e aparelhos de laboratório mais complexos, ou mesmo equipamentos radiológicos (Manfredini, 2006). 
Entretanto, o crescimento da demanda interna provocada pelo Plano Real, a par da estruturação do Sistema Único de Saúde (SUS), que ampliou a oferta de serviços, sua universalização e integralidade e o peso da demanda pública nesse mercado, foram responsáveis pela significativa expansão da indústria a partir da segunda metade da década de 1990. Os programas de investimento do governo federal na rede assistencial responderam por parte expressiva no dinamismo empresarial, a exemplo do projeto de Reforço à Reorganização do SUS (Reforsus, já finalizado) e dos financiamentos do Banco Nacional de Desenvolvimento Econômico e Social (BNDES) para a rede filantrópica, que viabilizaram a incorporação de equipamentos no sistema (Gadelha, 2007).

O dinamismo recente da indústria pode ser constatado pelo crescimento de $37 \%$ no número de empresas da indústria de 1999 a 2009 e de 307\% nas vendas nominais no mesmo período, o que, descontada a inflação, representa uma evolução real de 114,3\% (Iemi, 2010). De acordo com a Abimo (2012), em 2010 a indústria respondeu por um faturamento de $\mathrm{R} \$ 8,43$ bilhões e por exportações no valor de US\$ 633 milhões, tendo sido responsável pela geração de 104 mil empregos diretos e indiretos.

o mercado brasileiro é abastecido por produtores nacionais de portes pequeno e médio, por grandes multinacionais com atividades produtivas no país e por importação direta. Além de estrutura bastante segmentada, a indústria congrega um grande número de empresas de pequeno e médio portes, com receitas inferiores a $\mathrm{R} \$$ 50 milhões. A Tabela 24 apresenta a distribuição percentual de empresas, mão de obra, vendas e investimentos por porte das empresas, em 2009.

Tabela 24 - Mão de obra, vendas e investimentos por porte das empresas. Brasil - 2009 (em \%)

\begin{tabular}{l|c|c|c|c}
\hline PORTE & EMPRESAS & MÃ0 DE OBRA & VENDAS & INVESTIMENTOS \\
\hline Micro e pequeno & 25,7 & 7 & 0,61 & 0,6 \\
\hline Médio & 52,2 & 30,4 & 16,5 & 19,8 \\
\hline Médio/Grande & 11,8 & 21,8 & 17,9 & 11,9 \\
\hline Grande & 10,3 & 40,7 & 64,9 & 67,7 \\
\hline Total & 100 & 100 & 100 & 100 \\
\hline
\end{tabular}

Fonte: elaboração própria (GIS/Ensp/Fiocruz) com base em dados do Estudo Setorial da Indústria de Equipamentos OdontoMédico-Hospitalar e Laboratorial no Brasil (lemi, 2010).

Verifica-se que as empresas grandes, embora representem apenas 10\% do total, respondem pelos maiores percentuais em termos da mão de obra empregada, do faturamento e dos investimentos. Constata-se, igualmente, a predominância de empresas de porte médio na indústria, especializadas, em sua maioria, nos segmentos de baixa e média densidade tecnológica. Muitas delas têm formatos gerenciais inadequados para a competitividade, como estrutura familiar e baixo grau de profissionalização 
da gestão. Esses fatores explicam o afastamento da indústria da fronteira tecnológica no período recente, em termos dos grupos de produtos, a despeito do processo de expansão observado.

Quanto à origem do capital, quase $91 \%$ das empresas são de capital nacional, aproximadamente $6,5 \%$ são empresas estrangeiras e os $2,8 \%$ restantes são de empresas de capital misto (Abimo, 2010). Outra característica marcante é a concentração regional das indústrias: $76 \%$ das empresas localizam-se em São Paulo (capital $40 \%$ e interior 36\%), seguido do Rio de Janeiro com 6\%, Paraná com 5,6\%, Minas Gerais com $4 \%$ e o restante do país com $8 \%$ das empresas (Iemi, 2010).

Deve-se salientar que as grandes empresas são, basicamente, subsidiárias das grandes multinacionais ${ }^{20}$ com atuação significativa no segmento de insumos e material de consumo, que, nos últimos anos, tem respondido por quase metade das exportações anuais da indústria. Essas empresas produzem e exportam a partir do Brasil, e nelas os investimentos estão sujeitos às decisões estratégicas globais das grandes corporaçóes, o que tem levado a um grande movimento de abertura e fechamento de linhas de produtos (ABDI, 2009).

Pode-se considerar que a parcela dinâmica da indústria, referente às taxas de crescimento dos últimos anos, ao atendimento da demanda interna, às exportações sustentáveis e ao maior conteúdo tecnológico relativo, situa-se nos segmentos de: equipamentos médico-hospitalares (p. ex., monitores de sinais vitais multiparamétricos, ventiladores pulmonares, incubadoras para recém-nascidos, berços radiantes, equipamentos de fototerapia, esterilizadores médico-cirúrgicos, bombas de infusão, bisturis elétricos, equipamentos de mecanoterapia e fisioterapia, mesas cirúrgicas, focos cirúrgicos e camas hospitalares elétricas); de implantes (p. ex., próteses articulares, aparelhos biomecânicos para fraturas, válvulas cardíacas, odontológico); odontológico (p. ex., cimentos odontológicos e amálgamas, dentes artificiais de acrílico, equipamentos de uso odontológico, consultórios odontológicos, aparelhos dentários de brocar e aparelhos de raios X de acompanhamento odontológico). Os fabricantes dessas famílias de produtos representam quase $40 \%$ da produção nacional, inovam frequentemente suas linhas de produtos e alcançaram, nos últimos anos, presença relevante no mercado internacional (ABDI, 2009).

Nos segmentos de equipamentos e insumos para diagnóstico de imagem e laboratórios, por sua vez, a fragilidade da indústria nacional é patente em termos de competitividade internacional; as empresas nacionais suprem menos da metade da demanda interna, fornecendo produtos de menor valor agregado (ABDI, 2009). O segmento de radiologia, por exemplo, é, segundo Pieroni, Reis e Souza (2010), o mais afetado pela concorrência de produtos estrangeiros; nos últimos anos houve, inclusive, redução do número de empresas.

${ }^{20}$ Entre as empresas estrangeiras com atuação no Brasil incluem-se GE, Philips, Toshiba, Siemens, Kodak, Shimadzu, Becton Dickinson, Baxter, Edwards Lifesciences, Johnson \& Johnson, 3M, Saint Jude e Fresenius (Exportmed Brazil, 2004). 
A Tabela 25 apresenta a evolução, de 2003 a 2008, do faturamento da indústria desagregado por segmento.

Tabela 25 - Faturamento da indústria de equipamentos e materiais médico-hospitalares e odontológicos por segmento - 2003-2008 (em R\$ milhões)

\begin{tabular}{l|c|c|c|c|c|c|c}
\hline SEGMENTO & 2003 & 2004 & 2005 & 2006 & 2007 & 2008 & $\begin{array}{c}\text { TAXA DE CRESCIMENTO } \\
\text { ANUAL COMPOSTA (\%) }\end{array}$ \\
\hline Odontologia & 534 & 582 & 645 & 728 & 973 & 986 & 13,1 \\
\hline Laboratório & 586 & 618 & 663 & 768 & 769 & 808 & 6,6 \\
\hline Radiologia & 448 & 523 & 615 & 704 & 763 & 665 & 8,2 \\
\hline Equipamentos médicos & 957 & 1.006 & 1.076 & 1.115 & 1.238 & 1.279 & 6,0 \\
\hline Implantes & 516 & 565 & 630 & 731 & 778 & 777 & 8,6 \\
\hline Material de consumo & 1.832 & 2.063 & 2.354 & 2.682 & 2.760 & 2.762 & 8,6 \\
\hline
\end{tabular}

Fonte: Pieroni, Reis \& Souza, 2010.

Verifica-se um crescimento significativo de todos os segmentos no período considerado em termos da taxa anual de crescimento, não tendo ocorrido variações na participação dos diferentes segmentos no faturamento total da indústria. O segmento de material de consumo, cujos produtos são geralmente de baixo conteúdo tecnológico, detém a maior participação, com 37\% do faturamento total da indústria em 2008 . A parcela referente a equipamentos médicos e odontológicos também é relevante, com $18 \%$ do total em 2008.

A indústria respondia em 2009 por 0,27\% do valor bruto da produção da indústria brasileira, 0,37\% do valor da transformação industrial e 0,51\% do emprego total gerado no setor industrial; no período de 2007 a 2009 houve pequena melhoria em sua posição relativa (IBGE, 2012b).

Para avaliar o potencial de inovação da indústria no período recente, tomaram-se como base informações da Pintec/IBGE relativas a 2000, 2003, 2005 e 2008. A Tabela 26 apresenta alguns indicadores relacionados ao esforço inovativo da indústria de equipamentos e materiais médico-hospitalares e odontológicos comparativamente à indústria nacional, nos anos de 2000, 2003, 2005 e 2008. 
Tabela 26 - Estrutura do dispêndio em atividades inovativas na indústria de equipamentos e materiais médico-hospitalares e odontológicos - 2000, 2003, 2005 e 2008

\begin{tabular}{|c|c|c|c|c|c|c|c|c|c|c|c|c|}
\hline \multirow{3}{*}{ ڤ్ } & $\begin{array}{l}\text { 루 } \\
\text { 产 } \\
\text { o. }\end{array}$ & $\stackrel{m}{\rightarrow}$ & $\vec{\sigma}$ & $\tilde{\sigma}$ & $\stackrel{\infty}{0}$ & $\overrightarrow{0}$ & $\tilde{\sigma}$ & E & & $\underset{m}{\vec{m}}$ & 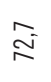 & \\
\hline & 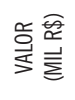 & Ĩ & 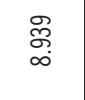 & 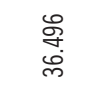 & $\begin{array}{l}\stackrel{\circ}{8} \\
\stackrel{9}{9}\end{array}$ & $\begin{array}{l}\text { శ్ } \\
\text { త্ }\end{array}$ & $\begin{array}{l}\stackrel{+}{心} \\
\stackrel{f}{*}\end{array}$ & 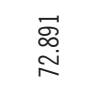 & & 总 & 1 & \\
\hline & 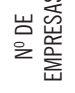 & $\widetilde{\widetilde{N}}$ & 0 & ఏ) & F & $\vec{\rho}$ & $\stackrel{\infty}{\not}$ & 号 & & $\stackrel{\infty}{\infty}$ & $\stackrel{\varnothing}{\Xi}$ & \\
\hline \multirow{3}{*}{ ठ } & 옳랄 & $\stackrel{\text { m }}{\sim}$ & $\overrightarrow{0}$ & m & 㞼 & $\overrightarrow{0}$ & g. & $\stackrel{2}{0}$ & $\tilde{\sigma}$ & $\stackrel{m}{D^{2}}$ & ㅇ. & \\
\hline & 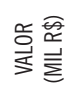 & 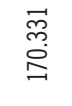 & 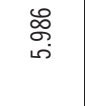 & $\begin{array}{l}\text { ָิ } \\
\text { 岕 }\end{array}$ & 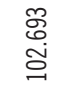 & $\begin{array}{l}\infty \\
\stackrel{\infty}{\oplus} \\
\stackrel{\oplus}{\oplus}\end{array}$ & 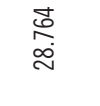 & 宫 & 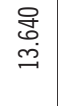 & 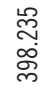 & 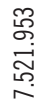 & \\
\hline & 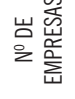 & $\stackrel{\circ}{\mathrm{m}}$ & $\ddot{m}$ & $\stackrel{\infty}{\oplus}$ & సี & 유 & $\stackrel{\vec{m}}{\vec{m}}$ & $\stackrel{\sim}{m}$ & $\stackrel{\sim}{\sim}$ & $\stackrel{\infty}{\not}$ & శ్ & $\infty$ \\
\hline \multirow{3}{*}{ ণ্ণ } & 홀를 & $\cong$ & $\vec{\sigma}$ & $\tilde{o}$ & $\hat{\sigma}$ & $\overrightarrow{0}$ & m. & $\stackrel{0}{\circ}$ & $\therefore$ & $\vec{m}$ & @े & \\
\hline & 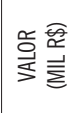 & 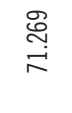 & 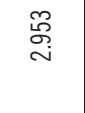 & 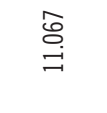 & 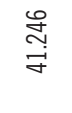 & $\underset{\dot{\sigma}}{\stackrel{g}{\sigma}}$ & 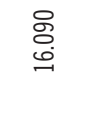 & 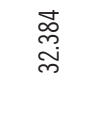 & 1 & 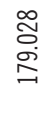 & 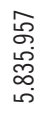 & \\
\hline & 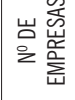 & 芩 & $\vec{m}$ & ing & $\underset{\sim}{\stackrel{\circ}{*}}$ & $\vec{\infty}$ & $\cong$ & 吉 & 1 & \& & $\stackrel{\stackrel{2}{\infty}}{\infty}$ & 5 \\
\hline \multirow{3}{*}{ 离 } & 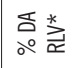 & $\stackrel{\infty}{-}$ & $\overrightarrow{0}$ & $\tilde{\sigma}$ & $\stackrel{\sim}{\sim}$ & $\approx$ & t & $\stackrel{\vec{\sigma}}{\circ}$ & $\therefore$ & 웅 & ㅇ. & \\
\hline & 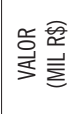 & 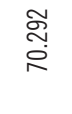 & $\underset{\sim}{\stackrel{\sim}{\sim}}$ & 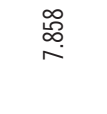 & $\stackrel{8}{\stackrel{\sim}{\sim}}$ & $\begin{array}{l}\infty \\
\stackrel{0}{0} \\
\infty\end{array}$ & $\begin{array}{l}\stackrel{0}{g} \\
\end{array}$ & 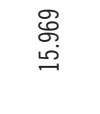 & 1 & 壱 & $\begin{array}{l}\infty \\
0 \\
\stackrel{+}{\sigma} \\
\stackrel{\sigma}{m} \\
\dot{m}\end{array}$ & \\
\hline & 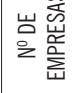 & 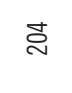 & $\vec{m}$ & 品 & $\stackrel{\sim}{\circ}$ & $\stackrel{\vec{\infty}}{\sigma}$ & త్త & 吉 & 1 & 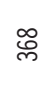 & $\stackrel{\Xi}{\curvearrowright}$ & G \\
\hline \multicolumn{2}{|c|}{ 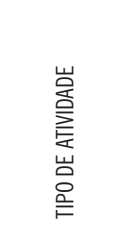 } & 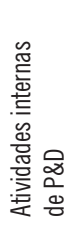 & 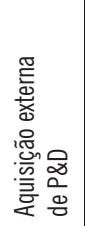 & 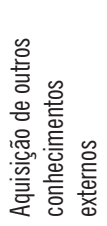 & 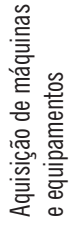 & 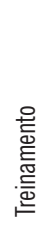 & 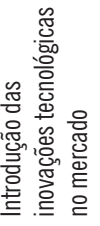 & 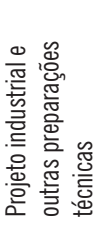 & 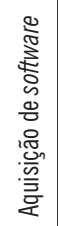 & 営 & 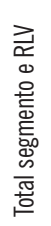 & ○ \\
\hline
\end{tabular}

* RLV - Receita Líquida de Vendas.

Fonte: elaboração própria com base nos dados obtidos na Pintec/IBGE, 2008 (IBGE, 2010b). 
Considerando a relação de gastos com atividades inovativas sobre vendas, verifica-se que as empresas da indústria de equipamentos médico-hospitalares e odontológicos apresentaram taxa de inovação bem acima da média nacional, situando-se em 5,29\% contra 2,8\% da média da indústria brasileira em 2005 (IBGE, 2007a), ${ }^{21}$ podendo ser caracterizada como de alta intensidade tecnológica. Entretanto, esse dinamismo relativo está muito aquém do verificado em nível mundial, como é claramente exemplificado pela relação dos gastos com atividades de $P \& D$ sobre vendas. Esse percentual é de $12,9 \%$ para os EUA, $10 \%$ para a Alemanha e 5,8\% para o Japão (Pammolli et al., 2005), enquanto que para a indústria de equipamentos brasileira foi de apenas 1,3\% em 2008 (IBGE, 2010b).

A fragilidade competitiva internacional das empresas da indústria também pode ser conferida pela evolução recente da balança comercial. De um lado, mesmo a produção de empresas situadas no território nacional ainda depende fortemente de insumos importados de maior conteúdo tecnológico, chegando a atingir 50\% em alguns segmentos. De outro, quando se considera a balança comercial como principal indicador da vulnerabilidade industrial, torna-se evidente a perda de competitividade da indústria, notadamente nos grupos mais dinâmicos e mais afetados pelos novos paradigmas tecnológicos: os aparelhos e equipamentos eletromédicos, odontológicos e laboratoriais, cujo processo produtivo vem sendo fortemente impactado pela microeletrônica.

Deve-se salientar que o déficit da indústria de equipamentos e materiais médicohospitalares e odontológicos representa cerca de $23 \%$ do total do CEIS, atrás da indústria de medicamentos (27\%) e de fármacos (24\%). O Gráfico 21 apresenta a evolução da balança comercial da indústria de 1996 a 2011.

O déficit comercial saltou de um patamar de US\$200 milhões no final da década de 1980 para um valor em torno de US\$ 800 milhões em meados dos anos 90, concentrando-se nos produtos eletrônicos (Gadelha, 2007). Mais recentemente, o saldo comercial apresentou uma redução no triênio 2002-2004, associado a desvalorização cambial, crise política, escassez de crédito, entre outros fatores, mas logo reverteu essa tendência, situando-se ao redor de US\$ 2.3 bilhões em 2011. O Gráfico 22 detalha a composição do saldo comercial de 1996 a 2011, desagregado por produtos eletrônicos e não eletrônicos, material de consumo e órteses e próteses, permitindo constatar a forte predominância de produtos eletrônicos, ou seja, os de maior conteúdo tecnológico.

O Gráfico 23 apresenta a evolução do saldo comercial de 1996 a 2011, por principais parceiros comerciais. Verifica-se a forte dependência das importações em relação aos polos dinâmicos da indústria, nomeadamente EUA, UE e Japão, ou seja, de produtos inovadores e de maior valor agregado e, de forma crescente, da China. Pode-se afirmar que a origem das importações brasileiras está fortemente concentrada nos EUA, na UE e no Japão; a participação desses três parceiros contabilizou $72 \%$

\footnotetext{
${ }^{21}$ Devido a mudança metodológica da Pesquisa Industrial de Inovação Tecnológica (Pintec/IBGE) 2008, não se dispõe dessa informação para esse ano para o segmento de equipamentos médicos.
} 
das importações totais da indústria em 2011 (Brasil. Ministério do Desenvolvimento, Indústria e Comércio Exterior, 2012). Do lado das exportações, destaque-se a forte presença de países do Mercado Comum do Sul (Mercosul) e do resto do mundo, de baixo dinamismo econômico, inclusive tecnológico, como destino de nossos produtos.

Cerca de metade da demanda brasileira é atendida por importações e inclui desde produtos de alto valor unitário, como equipamentos de ultrassom, tomógrafos, ressonância magnética, stents, luvas, marca-passos, até produtos de preço relativo baixo, vendidos em grande volume. Os principais importadores são hospitais públicos, instituições não lucrativas e empresas importadoras (Leão, Oliveira \& Albornoz, 2008).

Gráfico 21 - Balança comercial de equipamentos e materiais médico-hospitalares e odontológicos 1996-2011

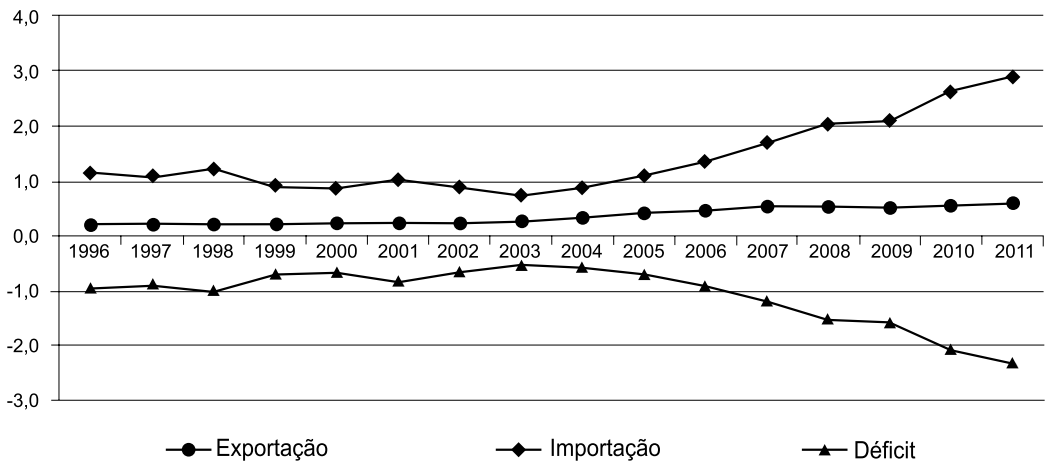

Fonte: elaboração própria (GIS/Ensp/Fiocruz), com base em dados do Alice Web (Brasil. Ministério do Desenvolvimento, Indústria e Comércio Exterior, 2012).

Gráfico 22 - Equipamentos e materiais médico-hospitalares e odontológicos: composição do saldo comercial - 1996-2011

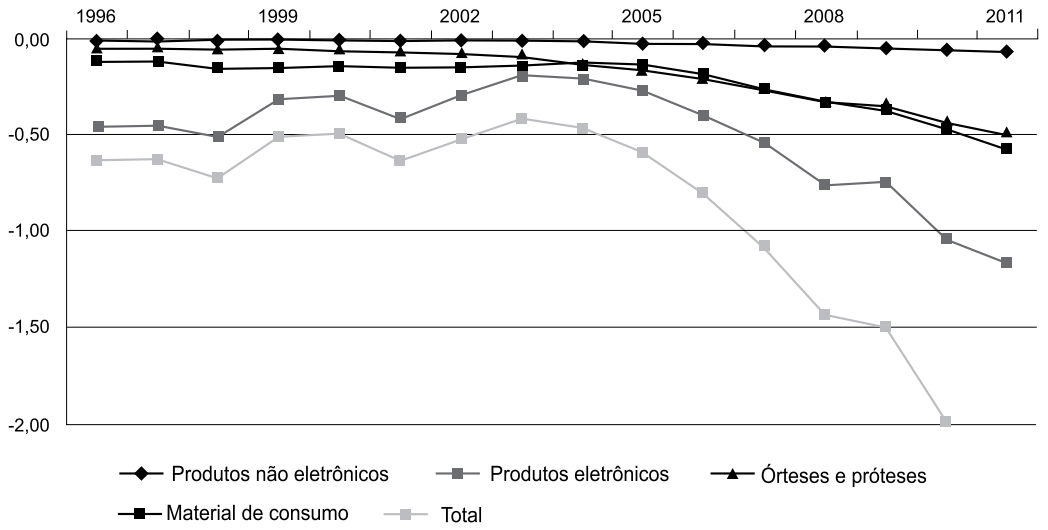

Fonte: elaboração própria (GIS/Ensp/Fiocruz), com base em dados do Alice Web (Brasil. Ministério do Desenvolvimento, Indústria e Comércio Exterior, 2012). 
Gráfico 23 - Equipamentos e materiais médico-hospitalares e odontológicos: principais parceiros comerciais - 1996-2011

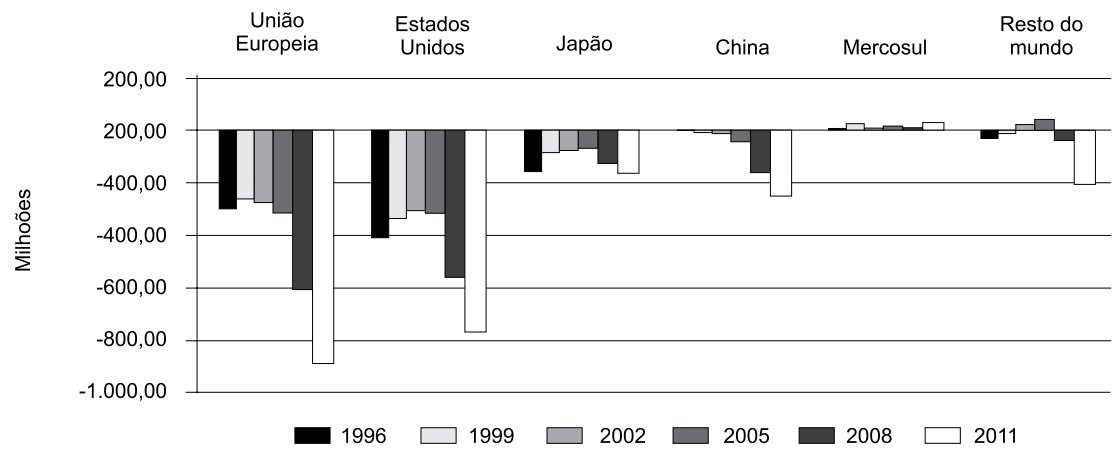

Fonte: elaboração própria (GIS/Ensp/Fiocruz), com base em dados do Alice Web (Brasil. Ministério do Desenvolvimento, Indústria e Comércio Exterior, 2012).

Os segmentos de radiologia e laboratório exemplificam a rápida evolução do déficit na balança comercial de equipamentos. Em 2002 apresentavam, respectivamente, déficits de US\$ 97 milhões e US\$ 40 milhões. Em 2006, tais valores eram de US\$ 156 milhões e US\$ 39 milhões, e em 2011 chegavam a US\$ 295 milhões e US\$ 116 milhões. Se somados os déficits, entre 2006 e 2011 os dois segmentos apresentaram um crescimento de $210 \%$. Destaque-se, também, o aumento relativo verificado no segmento de próteses e órteses, cujas importações cresceram 235\% de 2006 a 2011, passando de US\$ 270 milhões para US\$ 632 milhões (Brasil. Ministério do Desenvolvimento, Indústria e Comércio Exterior, 2012).

De 2006 a 2011, as exportações brasileiras conheceram um crescimento significativo, de US\$ 410 milhões para US\$ 596 milhões, ou seja, uma variação de 145\%. O único segmento que apresentou superávit comercial sistemático no período foi o de produtos de odontologia. Apesar do desempenho crescentemente positivo obtido entre 2002 e 2006, quando passou de US\$ 17 milhões para US\$ 45 milhões, em 2011 apresentou apenas um superávit de US\$ 12 milhões (Brasil. Ministério do Desenvolvimento, Indústria e Comércio Exterior, 2012).

Observa-se que no âmbito do CEIS esse foi um dos poucos segmentos que apresentaram respostas favoráveis no início da presente década, ampliando as exportações, ainda que a situação de dependência estrutural se tenha mantido nos produtos de maior densidade tecnológica, impondo um teto para a superação da vulnerabilidade internacional. Ou seja, há uma indústria importante de fabricação instalada no país e que apresentou boas respostas à demanda local, mas no contexto da revolução microeletrônica sua capacidade competitiva no futuro continua sendo ameaçada (Gadelha, 2007).

Deve-se ainda levar em consideração que o Brasil ocupa a $17^{\text {a }}$ posição no ranking mundial, uma posição privilegiada quando se considera que é praticamente o único 
país na América do Sul e Central dotado de uma indústria relativamente completa de fabricação de equipamentos e materiais médico-hospitalares e odontológicos.

\section{PERSPECTIVAS A MÉDIO E LONGO PRAZOS PARA OS INVESTIMENTOS}

Perspectivas a Médio Prazo: cenário possível

As previsões estimam que o faturamento do mercado mundial em 2012 deverá se situar em torno de US\$269, apresentando uma taxa de crescimento média de cerca de $6 \%$ a.a. Para o Brasil, as tendências indicam que o mercado nacional deverá atingir a marca de US\$ 3.4 bilhões, o que representa uma taxa de crescimento média de cerca de 3,4\% a.a. ${ }^{22}$ A Tabela 27 apresenta a evolução do faturamento dos mercados mundial e brasileiro para esses equipamentos e materiais de 2008 a 2012.

Tabela 27 - Faturamento do mercado mundial e mercado brasileiro de equipamentos e materiais médico-hospitalares e odontológicos - 2008-2012

\begin{tabular}{l|r|r|r|r|r}
\hline \multicolumn{7}{c|}{} & \multicolumn{1}{c}{ US\$ MLLÕES } \\
\hline & 2008 & 2009 & 2010 & 2011 & 2012 \\
\hline Mercado mundial & 210.192 & 223.262 & 237.289 & 252.394 & 268.853 \\
\hline Mercado brasileiro & 2.987 & 3.085 & 3.187 & 3.295 & 3.408 \\
\hline
\end{tabular}

Fonte: The World Medical Markets Fact Book, 2008.

O Brasil, que em 2009 ocupava a $17^{\text {a }}$ posição nesse mercado, deverá passar para a

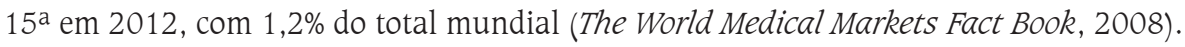

Relativamente às perspectivas de médio prazo para o mercado brasileiro, alguns elementos que já se fazem sentir atualmente deverão impactar, direta ou indiretamente, o desenvolvimento da indústria no futuro próximo. São eles: convergência políticoinstitucional; ampliação dos investimentos externos diretos; aquisições; crescente uso das Tecnologias da Informação e Comunicação (TICS).

\section{CONVERGÊNCIA POLÍTICO-INSTITUCIONAL}

Para a indústria de equipamentos e materiais médico-hospitalares e odontológicos em particular, apresentam-se algumas iniciativas que configuram uma convergência político-institucional favorável. Particularmente, a adoção do enfoque sistêmico decorrente da concepção do CEIS expandiu a prioridade que já vinha sendo conferida na agenda política à área farmacêutica, com a Política Industrial e de Comércio Exterior

\footnotetext{
${ }^{22}$ As previsões apontam para a seguinte distribuição do mercado brasileiro por tipo de equipamento: material de consumo, 22,5\%; diagnóstico por imagem, 21,8\%; odontológico, 4,4\%; ortopédico, 22,0\%; outros, 29,3\% (The World Medical Markets Fact Book, 2008).
} 
lançada em 2003 para o campo da indústria de equipamentos e materiais (Brasil. Ministério do Desenvolvimento, Indústria e Comércio Exterior, 2003). Dessa forma, a política para o fomento e adensamento tecnológico do complexo da saúde passa a contemplar os dois subsistemas que conformam o componente industrial do sistema produtivo da saúde, ficando ainda a necessidade de incorporação das necessidades ditadas pelo segmento de serviços (que refletem as demandas da saúde coletiva) de forma mais sistêmica.

Assim, o Subsistema de Base Mecânica, Eletrônica e de Materiais ganha prioridade nas seguintes iniciativas e programas de relevância nacional:

- Política de Desenvolvimento Produtivo (PDP), lançada em maio de 2008 pela Presidência da República, que prevê o estímulo à competitividade da empresa brasileira, a substituição competitiva das importações e o apoio à infraestrutura tecnológica e de qualidade industrial e às atividades de P\&D.

- Programa Mais Saúde, do Ministério da Saúde (MS), lançado em dezembro de 2007. No caso da indústria de equipamentos e materiais médico-hospitalares e odontológicos, uma das metas é substituir $25 \%$ da demanda de equipamentos e materiais do SUS por produção nacional, mediante medidas de fomento à capacidade produtiva e de inovação das empresas nacionais, em parceria com o BNDES e a Financiadora de Estudos e Projetos (Finep) (Brasil. Ministério da Saúde, 2007).

- PAC da Inovação do Ministério da Ciência, Tecnologia e Inovação (MCTI), incluindo os "insumos em saúde" na prioridade do esforço de Ciência, Tecnologia e Inovação (CT\&I), incorporando em suas prioridades o Subsistema de Equipamentos e Materiais em Saúde e mobilizando, inclusive, as agências da área de Ciência e Tecnologia (C\&T), como a Finep e o Conselho Nacional de Desenvolvimento Científico e Tecnológico (CNPq).

- Lançamento pelo BNDES, no fim de 2007, do Programa de Apoio ao Desenvolvimento da Cadeia Produtiva Farmacêutica (Profarma 2), renomeado como Programa de Apoio ao Desenvolvimento do Complexo Industrial da Saúde, estendido, portanto, para a indústria de equipamentos e materiais médico-hospitalares e odontológicos.

Nesse contexto político-institucional favorável, diversos instrumentos de política governamental passaram a priorizar o subsistema ora em análise, a exemplo do Fundo Setorial de Saúde (Finep, 2008) e do Programa Brasileiro de Avaliação de Conformidade e Atividades de Metrologia, o qual contempla diversos produtos dos segmentos industriais da base mecânica, eletrônica e de materiais para a saúde (Inmetro, 2008).

AmpliaÇÃO dOS INVESTIMENTOS EXTERNOS DIRETOS

O crescimento do mercado brasileiro de equipamentos médico-hospitalares, associado à ampliação do sistema de saúde suplementar, à taxa de câmbio, à ampliação 
do crédito para aquisição de equipamentos, ao lançamento do PAC Saúde, entre outros, tem atraído a atenção das grandes multinacionais da indústria. o Brasil deverá receber, a partir de 2012, investimentos de quase US\$ 1 bilhão para a construção de pelo menos três fábricas, duas das quais de produção de equipamentos de alta tecnologia para doenças consideradas prioritárias, como câncer (Valor Econômico, 2012a). Segundo apurado pelo Valor Econômico de janeiro de 2012, o MS estabeleceu conversas com pelo menos cinco multinacionais (a sueca Elekta, as americanas GE e Varian, a alemã Siemens e a holandesa Philips) para negociar a nacionalização e transferência tecnológica de equipamentos (e medicamentos), com o objetivo de reduzir o déficit da balança comercial da saúde (Valor Econômico, 2012b).

A GE, com fábrica já inaugurada em Contagem, MG, em 2010, planeja acelerar a introdução de novos equipamentos que passarão a ser produzidos no país. A empresa começou produzindo equipamentos de raios X, no fim de 2011 passou a montar máquinas de tomografia computadorizada e prevê a produção de máquinas de ressonância magnética ainda em 2012. A estratégia da companhia é, na primeira etapa, realizar a montagem dos novos equipamentos no Brasil, para depois dar conteúdo nacional aos produtos, por meio, sobretudo, da transferência de tecnologia para os fornecedores das peças, de modo a atingir $60 \%$ de nacionalização em tudo o que for produzido na nova fábrica (Valor Econômico, 2012c).

A empresa americana Varian, especializada em tratamentos de radioterapia, estava em negociação, em janeiro de 2012, para iniciar a produção de equipamentos no Brasil e a Siemens estaria preparando um plano para nacionalizar equipamentos de radioterapia, sobretudo pela possibilidade de se tornar plataforma de exportações nessa área. A holandesa Philips, por sua vez, já produz no país equipamentos de alta tecnologia, como raios X e mamógrafo digital (Valor Econômico, 2012a).

o Gráfico 24 apresenta a evolução de 2002 a 2006 dos investimentos externos diretos na indústria.

Constata-se um crescimento significativo, sobretudo a partir de 2003; desse ano até 2006 verifica-se uma variação positiva de praticamente $435 \%$. No período considerado, deve-se ressaltar que a indústria de equipamentos propriamente dita respondeu por mais de $80 \%$ desses recursos, em detrimento da indústria de materiais. Países Baixos, Suíça, Espanha, Suécia e EUA responderam por $87 \%$ desses recursos (Leão, Oliveira \& Albronoz, 2008). 
Gráfico 24 - Investimentos externos diretos na indústria de equipamentos e materiais médicohospitalares e odontológicos - 2002-2006 (em US\$ mil)

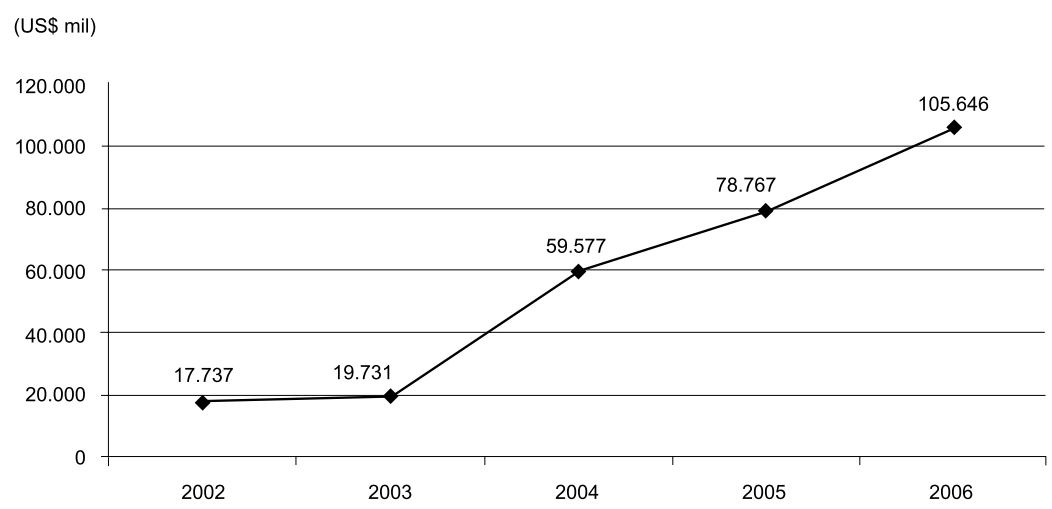

Fonte: Leão, Oliveira \& Albronoz, 2008.

\section{AQUIIIIÇÕES}

Destaquem-se, também, as aquisições recentes no setor. O grupo norte-americano $3 \mathrm{M}$, segunda maior empresa do setor no mundo, com $34 \%$ do mercado de produtos ortodônticos, tem expandido sua atuação na América Latina, onde já lidera, com 36\% do mercado. Tem sido importante para a consolidação de sua posição a aquisição de empresas brasileiras: em 2006, a 3M adquiriu a divisão de segurança da Pomp Produtos Hospitalares e Segurança do Trabalho Ltda, fornecedora de produtos para a proteção individual do trabalhador, o que reforça a posição da adquirente no mercado hospitalar nacional (Gellermann \& Leonardo, 2006). Um ano depois a empresa adquiriu a Abzil Indústria e Comércio, e em 2008 inaugurou novas instalações de sua fábrica em São José do Rio Preto, SP, que recebeu investimentos de R\$ 14 milhões para triplicar sua capacidade de fabricação de produtos ortodônticos (Camarotto apud Unicamp \& ABDI, 2009).

Em 2007 a Philips adquiriu a VMI, empresa que mantinha forte presença no mercado de raios X e nos segmentos de cateterismos, mamografia e ultrassom (Saúde Web, 2007), e em 2008 adquiriu a Dixtal, o maior fabricante brasileiro de monitores de leitos de hospital e aparelhos médicos para respiração e anestesia (Saúde Web, 2008b). Nesse mesmo ano a Philips começou a produzir aparelhos de ressonância magnética no Brasil. A expectativa da empresa é que $60 \%$ das peças passem a vir de fornecedores nacionais mediante investimentos em transferência de tecnologia da matriz (Philips, 2008). Atualmente, a empresa já está produzindo tomografia computadorizada e equipamentos de mamografia e aparelhos de raios X digitais. Ademais, em 2010 foram adquiridas as empresas de softwares clínicos Tecso e Wheb, para complementar o portfólio de produtos oferecidos (Philips, 2011; Valor Econômico, 2012a) e em 2011 a empresa anunciou que iria investir na ampliação das linhas de produção da fábrica de Lagoa Santa, MG (Diário do Comércio, 2011). Além de atender 
o mercado interno, a Philips planeja exportar seus equipamentos em um primeiro momento para o Mercosul e, em seguida, para outros mercados emergentes, como a China e a Índia (Saúde Web, 2008a).

Também vale ressaltar as consequências, para o mercado brasileiro, da aquisição (em agosto de 2010), pela Roche, da americana Bioimagene, especializada em telepatologia, diagnósticos digitais de tecidos humanos, técnica utilizada para detectar doenças como o câncer. Essa nova aquisição, somada à realizada em 2008, quando a Roche adquiriu a Ventana, produtora de equipamentos automáticos para esses mesmos exames, posiciona a empresa como uma das principais fornecedoras globais de tecnologia para laboratórios de patologia. A nova posição implica mudanças no mercado brasileiro, na medida em que a meta da nova divisão de diagnósticos de tecidos humanos da empresa é instalar até 2015 os novos equipamentos em aproximadamente 50\% dos 215 laboratórios latino-americanos, 110 dos quais se localizam no Brasil (Brasil Econômico, 2010).

Crescente uso das Tecnologias da Informação e Comunicação (TICS)

Em busca de redução de custos, rapidez no atendimento e aumento da qualidade do diagnóstico, os grandes hospitais e instituições médicas investem em programas e sistemas de informação, evidenciando as articulações entre os subsistemas do CEIS.

O setor de softwares para gestão hospitalar, instalado no Brasil há dez anos, teve seu crescimento significativamente intensificado a partir de 2009. Atualmente, o setor responde por $2 \%$ da indústria brasileira de softwares, movimentando por ano $\mathrm{R} \$ 500$ milhões (Valor Econômico, 2011e). Segundo reportagem do jornal Valor Econômico de 29 de julho de 2011, as empresas da área têm expandido significativamente suas atividades e prevê-se que este segmento crescerá seis vezes nos próximos cinco anos.

Em 2008, o Hospital das Clínicas comprou da Philips sistemas de armazenamento e distribuição digital de imagem médicas que, além dos equipamentos de raios X digitais e da plataforma de tecnologia da informação, envolveu o fornecimento de serviços de consultoria de gestão, diagnóstico das necessidades, melhoria da produtividade e planejamento estratégico. O sistema representa uma economia de cerca de $\mathrm{R} \$ 1,5$ milhão por ano, com a eliminação de custos com compras de filmes e revelações, além de um ganho de 30\% em produtividade (Gazeta Mercantil, 2008).

No mesmo ano, com tecnologia da Agfa Health Care do Brasil, o Hospital SírioLibanês inaugurou o Centro de Diagnóstico por Imagem (CDI) e sala de cirurgia inteligente amparado por sistema Pacs (Picture Archiving and Communication System). Tal sistema permite digitalizar, armazenar e consultar em rede todas as imagens dos exames dos pacientes em modalidades médicas como ressonância magnética, tomografia, ultrassonografia, entre outros $(I n, 2008){ }^{23}$

${ }^{23}$ A mudança do sistema analógico para o digital por parte das instituições de saúde deve representar oportunidades de negócios da ordem dos US\$ 300 milhões, segundo o Hospital Sírio-Libanês (In, 2008). 
O Hospital Samel, de Manaus, inaugurou em outubro de 2011 seu CDI, com equipamentos de última geração, no qual foram investidos $\mathrm{R} \$ 2$ milhões. O novo sistema vai permitir que todos os exames realizados no CDI cheguem digitalizados, em tempo real, a todos os setores do hospital via computador (Saúde Web, 2011).

GE e Intel anunciaram, em agosto de 2010, uma joint venture para a área da saúde, com o objetivo de desenvolver e comercializar produtos, serviços e tecnologias que promovem a vida saudável e independente em casa. Ajoint venture se concentrará nos segmentos de gerenciamento de doenças crônicas, vida independente e tecnologias assistidas (O Globo, 2010).

A Totvs, que em dezembro de 2010 adquiriu a Gens Tecnologia e Informática, especializada em softwares de gestão para a saúde, afirma que esta é uma das quatro principais áreas de negócios da empresa. E a Philips estuda adquirir outras empresas de softwares no país para complementar seu portfólio (Valor Econômico, 2011e).

A MTM Tecnologia, que entrou neste segmento há dois anos com um aplicativo de prontuário eletrônico para smartphones, já teve seu produto adotado pelo Hospital Israelita Albert Einstein (HIAE), pelo Hospital Espanhol, em Salvador, e o exportou para 1,2 mil clínicas dos Estados Unidos e da Inglaterra (Valor Econômico, 2011e).

Segundo o jornal Valor Econômico (2011e), a americana InterSystems prevê um aumento de $50 \%$ na receita gerada em sua operação brasileira, como resultado, em grande parte, de três grandes projetos públicos no país, tendo já realizado o cadastro do prontuário eletrônico de 2,5 milhões de pacientes. Outras duas empresas que se posicionam para abastecer a demanda pública são a brasileira MV Sistemas e a portuguesa Alert, que atua no Brasil desde 2007. Em julho de 2011 esta empresa mantinha contratos com 35 hospitais, que atendem 12 mil pessoas por dia, aos quais passaram a se somar outros contratos com vinte hospitais da rede pública do estado de Minas Gerais e com a Beneficência Portuguesa de São Paulo. As expectativas de crescente informatização das instituições de saúde no Brasil são significativas, visto que apenas $15 \%$ dos 6,3 mil hospitais públicos e privados do país contam com sistemas informatizados (Valor Econômico, 2011e).

No que tange aos órgãos de saúde pública, a adoção de dispositivos de telemedicina, processo que começou a ganhar força em 2010, entrou em nova fase, com a inclusão de mais recursos tecnológicos em 2011. Os resultados obtidos, como a redução da mortalidade e do tempo de internação de infartados, levaram os governos responsáveis pelos primeiros movimentos a estudar a expansão do atendimento à distância. Entre as inovações previstas para o segundo semestre de 2011, estavam a adoção de aparelhos de ultrassonografia à distância e a melhoria do sistema de transmissão de dados por radiofrequência (Valor Econômico, 2011f).

Estes elementos em conjunto - contexto político-institucional favorável, investimentos externos diretos, aquisições e impacto das TICs no sistema produtivo da saúde - deverão promover impactos significativos no modus operandi da indústria nacional. 
O crescente interesse das multinacionais pelo mercado brasileiro, seja sob a forma de investimentos externos diretos, seja via aquisições de empresas locais, deverá se intensificar no futuro próximo. A busca por vantagens competitivas específicas de alguns players internacionais no mercado brasileiro, a exemplo da Siemens, GE e Philips - melhor adaptação do produto à demanda local, melhor qualidade, custos mais baixos para os clientes, capacidade de atendimento às exigências dos consumidores, entre outras - deverá induzir, no âmbito da mútua interdependência oligopolista, movimentos similares de outros competidores mundiais.

O Quadro 9 sintetiza o cenário possível a médio prazo, apresentando os principais determinantes da dinâmica do investimento esperado, metas para 2012, impactos sobre os investimentos do segmento e efeitos esperados sobre a economia.

Quadro 9 - Perspectivas de médio prazo. Cenário possível - 2012

\begin{tabular}{|c|c|c|c|}
\hline $\begin{array}{l}\text { DETERMINANTES DA DINÂMICA } \\
\text { DO INVESTIMENTO ESPERADO }\end{array}$ & METAS PARA 2012 & $\begin{array}{l}\text { IMPACTOS NOS INVESTIMENTOS } \\
\text { DO SEGMENTO }\end{array}$ & $\begin{array}{l}\text { EFEITOS ESPERADOS NO } \\
\text { CONJUNTO DA ECONOMIA }\end{array}$ \\
\hline $\begin{array}{l}\text { Ambiente político institucional } \\
\text { favorável. } \\
\text { Investimentos externos } \\
\text { diretos em produtos } \\
\text { existentes. } \\
\text { Investimentos externos } \\
\text { diretos em novos produtos. } \\
\text { Aquisições. } \\
\text { Crescente uso das TICs. } \\
\text { Crescente articulação } \\
\text { entre o Subsistema de } \\
\text { Base Mecânica, Eletrônica } \\
\text { e de Materiais e as novas } \\
\text { tendências nos serviços de } \\
\text { saúde. }\end{array}$ & $\begin{array}{l}\text { Implementação da PDP, Mais } \\
\text { Saúde e demais políticas } \\
\text { para o CEIS. } \\
\text { Aumento dos gastos públicos } \\
\text { em saúde para } 5 \% \text { do PIB. } \\
\text { Crescimento médio da } \\
\text { indústria de } 3,4 \% \text { a.a. } \\
\text { Equilíbrio competitivo da } \\
\text { balança comercial. } \\
\text { Crescimento dos gastos em } \\
\text { P\&D/vendas (para } 3 \% \text { ). } \\
\text { Desenvolvimento tecnológico } \\
\text { dos } 25 \text { principais } \\
\text { equipamentos e materiais } \\
\text { prioritários no âmbito do SUS. }\end{array}$ & $\begin{array}{l}\text { Ampliação dos investimentos } \\
\text { externos, novos entrantes } \\
\text { e, concomitantemente, } \\
\text { acirramento da concorrência, } \\
\text { aumento das barreiras } \\
\text { à entrada e maior } \\
\text { concentração. } \\
\text { Expansão da capacidade } \\
\text { produtiva associada com } \\
\text { aumento na escala de } \\
\text { produção. } \\
\text { Aumento na capacitação de } \\
\text { empresas para a inovação } \\
\text { incremental. } \\
\text { Fortalecimento do sistema } \\
\text { nacional de inovação } \\
\text { em saúde e sua maior } \\
\text { articulação com o sistema } \\
\text { de saúde. } \\
\text { Consolidação patrimonial e } \\
\text { novos modelos gerenciais. }\end{array}$ & $\begin{array}{l}\text { Expansão do PIB e geração } \\
\text { de emprego (cerca de } 200 \text { mil } \\
\text { empregos diretos e indiretos). } \\
\text { Desenvolvimento tecnológico } \\
\text { e industrial / capacitação } \\
\text { inovativa em equipamentos e } \\
\text { materiais estratégicos. } \\
\text { Aumento da participação do } \\
\text { segmento no PIB em pelo } \\
\text { menos } 1 \% \text {. } \\
\text { Redução do déficit na balança } \\
\text { comercial no complexo da } \\
\text { saúde. } \\
\text { Aumento do dispêndio } \\
\text { em P\&D e com atividades } \\
\text { inovativas do setor privado. }\end{array}$ \\
\hline
\end{tabular}

CEIS - Complexo Econômico-Industrial da Saúde; P\&D - Pesquisa e Desenvolvimento; PDP - Política de Desenvolvimento Produtivo; PIB - Produto Interno Bruto; TIC - Tecnologia da Informação e Comunicação.

Fonte: elaboração própria. Referências: Política de Desenvolvimento Produtivo - PDP (Brasil. Ministério do Desenvolvimento, Indústria e Comércio, 2008), Programa Mais Saúde (Brasil. Ministério da Saúde, 2007) e PAC da Inovação (Brasil. Ministério da Ciência e Tecnologia e Inovação, 2007). 
Nesse cenário, a definição de prioridades no Brasil para que as empresas nacionais tenham reforçadas suas vantagens competitivas e sejam conduzidas a patamares de maior densidade tecnológica em termos dos produtos oferecidos se torna crucial. Propõe-se, nesse sentido, a identificação de nichos de mercado para a promoção de estratégias de especialização, em conjunção com o uso do poder de compra do Estado. De acordo com a Abimo (2010), o poder público representava 21,5\% das compras da indústria em 2009; todavia, como ressaltam Pieroni, Reis e Souza (2010), parte significativa das compras de entidades privadas é reembolsada pelo sistema público de saúde, o que, na prática, sinaliza forte potencialidade da intensificação do uso de poder de compra do Estado, uma vez que 50\% da demanda dos produtos vendidos pela indústria são viabilizados, direta e indiretamente, por recursos públicos. Assim, o Estado, em seu papel de grande consumidor de bens e serviços da indústria, pode direcionar o desenvolvimento desta, por meio do estabelecimento de compras preferenciais. Adota-se, para tanto, o disposto na Portaria n. 978, de maio de 2008, do MS, que identifica um conjunto de equipamentos e materiais de consumo prioritários no âmbito do SUS como itens que devem receber apoio em termos do adensamento tecnológico envolvido.

A Tabela 28 apresenta a relação de equipamentos constantes da Portaria n. 978, que lista os equipamentos prioritários segundo o MS. Além da listagem, são apresentados também a densidade tecnológica envolvida, os gastos diretos do SUS em 2006 com aquisição desses equipamentos e respectivo percentual em relação ao total, a qualificação quanto à produção nacional e exemplos de agentes empresariais. ${ }^{24}$ A Tabela 29 apresenta as mesmas informações em relação a materiais de consumo.

Na primeira fase de implementação do Programa Mais Saúde (2008-2010), já foram investidos mais de $\mathrm{R} \$ 15$ milhões em parceria com o BNDES e a Finep, para fomentar a capacidade produtiva e de inovação nas indústrias privadas nacionais de equipamentos e materiais médico-hospitalares e odontológicos (Brasil. Ministério da Saúde, 2010).

Paralelamente, propõe-se agregar à referida listagem outros itens também considerados prioritários, ${ }^{25}$ agrupados entre aqueles para os quais o país já dispõe de alguma capacitação tecnológica e industrial e que demandam medidas de reforço/ ampliação de suas vantagens competitivas, e aqueles em que o país não dispõe de capacidades, sendo inteiramente dependente de importações, e para os quais precisa construir competitividade.

\footnotetext{
${ }^{24}$ Em maio de 2010, a Portaria n. 1.284 do Ministério da Saúde atualizou a anterior. De acordo com a nova portaria, os critérios utilizados na seleção desses produtos foram: aderência aos programas desenvolvidos pelo MS; nível de produção nacional; número de fabricantes no país; destacado índice de queixas técnicas ou eventos adversos notificados à Anvisa associados a produtos nacionais; demanda técnica para certificação de produtos.

${ }^{25}$ Itens definidos a partir de discussões realizadas com a Abimo.
} 
Tabela 28 - Equipamentos prioritários

\begin{tabular}{|c|c|c|c|c|}
\hline PRODUTO & $\begin{array}{l}\text { DENSIDADE } \\
\text { TECNOLÓGICA }\end{array}$ & $\begin{array}{l}\text { SUS (2006) } \\
\text { R\$ MIL }\end{array}$ & $\begin{array}{l}\text { PRODUÇÃO } \\
\text { NACIONAL }\end{array}$ & AGENTES \\
\hline Aparelho de anestesia & Média & $\begin{array}{r}6.567 \\
(1,47 \%)\end{array}$ & Regular & $\begin{array}{l}\text { HB Hospitalar, Intermed, JG Moriya, } \\
\text { Dixtal, K. Takaoka }\end{array}$ \\
\hline Aparelho de endoscopia & Baixa & nd & Regular & Endoview, Sawae \\
\hline Aparelho de mamografia & Alta/Média & $\begin{array}{r}883 \\
(0,20 \%)\end{array}$ & Regular & VMI \\
\hline Aparelho de raios $X$ & Alta/Média & $\begin{array}{r}9.693 \\
(2,16 \%)\end{array}$ & Regular & $\begin{array}{l}\text { Crx, Ray Tec, Sawae, VMI, Astex, } \\
\text { Prodental, Procion }\end{array}$ \\
\hline Aparelho de ultrassom & Alta/Média & $\begin{array}{r}5.974 \\
(1,33 \%)\end{array}$ & Inexistente & \\
\hline Cardioversores e desfibriladores & Baixa & $\begin{array}{r}707 \\
(0,16 \%)\end{array}$ & Regular & Instramed, TEB \\
\hline Eletrocardiógrafo & Baixa & $\begin{array}{r}5.635 \\
(1,26 \%)\end{array}$ & Regular & CMOS Drake, Dixtal, TEB \\
\hline Equipamento de hemodiálise & Alta/Média & $\begin{array}{r}873 \\
(0,19 \%)\end{array}$ & Inexistente & \\
\hline $\begin{array}{l}\text { Equipamento para avaliação } \\
\text { da qualidade de imagem e da } \\
\text { segurança e desempenho de } \\
\text { equipamentos eletromédicos }\end{array}$ & Média & nd & Inexistente & \\
\hline $\begin{array}{l}\text { Equipamento para diagnóstico } \\
\text { in vitro e in vivo }\end{array}$ & Alta & nd & Inexistente & \\
\hline $\begin{array}{l}\text { Freezer/conservador de amostras, } \\
\text { sangue, vacinas }\end{array}$ & Baixa & $\begin{array}{r}2.488 \\
(0,55 \%)\end{array}$ & Regular & Fanem, Indrel \\
\hline $\begin{array}{l}\text { Monitores cardíacos e } \\
\text { multiparâmetros }\end{array}$ & Alta/Média & $\begin{array}{r}17.519 \\
(3,91 \%)\end{array}$ & Regular & Dixtal, Omnimed, Instramed, TEB \\
\hline Oxímetro de pulso & Baixa & $\begin{array}{r}707 \\
(0,16 \%)\end{array}$ & Regular & $\begin{array}{l}\text { JG Moriya, K. Takaoka, Instramed, } \\
\text { Gicante Recém-Nascido, CMOS Drake }\end{array}$ \\
\hline Ventilador pulmonar & Média/Baixa & $\begin{array}{r}20.896 \\
(4,66 \%)\end{array}$ & Regular & Intermed, JG Moriya, Dixtal, K. Takaoka \\
\hline $\begin{array}{l}\text { Receptor/detector digital de } \\
\text { imagem }\end{array}$ & Alta & nd & Inexistente & \\
\hline
\end{tabular}

* nd - não disponível.

Fonte: elaboração própria (GIS/Ensp/Fiocruz). 
Tabela 29 - Materiais de consumo prioritários

\begin{tabular}{l|c|c|c|c}
\hline PRODUTO & $\begin{array}{c}\text { DENSIDADE } \\
\text { TECNOLÓGICA }\end{array}$ & $\begin{array}{c}\text { SUS (2006) } \\
\text { R\$ MLL }\end{array}$ & $\begin{array}{c}\text { PRODUÇÃO } \\
\text { NACIONAL }\end{array}$ & AGENTES \\
\hline Média & nd & Regular & $\begin{array}{c}\text { Braile, HB Biopróteses, } \\
\text { Injex, Mark Med, Plascap, } \\
\text { Sci Tech, Ventura }\end{array}$ \\
\hline Endopróteses vasculares & Alta/Média & nd & Inexpressiva & Nano, Endoluminal, Braile \\
\hline Filtro de veia cava & Média & nd & Inexpressiva & Braile \\
\hline $\begin{array}{l}\text { Implantes ortopédicos } \\
\text { Indutores, bainhas }\end{array}$ & Alta/Média & nd & Regular & $\begin{array}{c}\text { Baumer, Bio Engenharia, Impol, IOL, } \\
\text { Ortobio, Spine Implantes }\end{array}$ \\
\hline Marca-passo implantável & Média & nd & Inexistente & Inexistente \\
\hline $\begin{array}{l}\text { Sensores de oximetria } \\
\text { e capnografia }\end{array}$ & Baixa & nd & Inexpressiva & Dixtal \\
\hline \begin{tabular}{l} 
Stents \\
\hline
\end{tabular} & Alta/Média & nd & Regular & Braile, Scitech \\
\hline
\end{tabular}

nd - não disponível.

Fonte: elaboração própria (GIS/Ensp/Fiocruz).

Dos itens cujas vantagens competitivas é preciso reforçar/ampliar, salientam-se:

- sistemas de infusão enteral e parenteral;

- implantes e próteses;

- equipamentos médicos fundamentados em ótica, endoscópios e similares;

- neonatal: incubadoras de recém-nascidos;

- equipamentos e materiais odontológicos.

Quanto aos itens para os quais é preciso construir competitividade e que representam novas oportunidades em termos do adensamento tecnológico nacional, salientam-se:

- chips para a indústria de equipamentos hospitalares, que podem ser utilizados em inúmeros aparelhos eletromédicos;

- hemodialisadores: filtros utilizados em hemodiálise;

- artigos e instrumentos cirúrgicos (instrumental) fabricados a partir de plásticos de engenharia, e não pelo método tradicional de indústrias metalúrgicas;

- equipamentos automatizados para diagnóstico;

- imagens médicas: receptores, aparelhos de ultrassom, radiologia digital; 
- tecnologia de materiais, sendo algumas das principais oportunidades o desenvolvimento e uso de titânio e suas ligas, de polímeros de ultra-alta densidade para o caso de implantes, materiais cerâmicos como a hidroxiapatita usada em processos de osseointegração em aplicações odontológicas, e plásticos de engenharia e ligas metálicas para a fabricação de instrumental cirúrgico.

Perspectivas a Longo Prazo: cenário desejável

Destacam-se a seguir os principais elementos no campo da saúde que terão influência a longo prazo no comportamento da indústria de equipamentos e materiais médico-hospitalares e odontológicos no Brasil (Exportmed Brazil, 2004; ABDI, 2009).

PRESSÕES POR REDUÇ̃̃o DE CUSTOS

O envelhecimento da população e a ampliação dos serviços de saúde com vista à universalização e integralização são dois elementos que, conjugados, deverão exercer forte pressão sobre os gastos públicos e privados com a saúde. Nesse cenário, a indústria de equipamentos deverá sofrer fortes e crescentes pressões para que seus desenvolvimentos tecnológicos levem em conta o aprimoramento da qualidade dos padrões de tratamento e diagnóstico que os torne mais efetivos, rápidos, seguros e, preferencialmente, não invasivos para uma grande variedade de doenças, mas considerem também sua capacidade de reduzir o custo dos tratamentos (Ettlinger, 2005).

MEDICINA PREVENTINA

Em um quadro geral de ampliação de serviços de saúde e seus custos, dever-se-á dar importância crescente à medicina preventiva, isto é, ao diagnóstico precoce. Os serviços de saúde em geral e os equipamentos neles utilizados deverão responder ao caráter cada vez mais preventivo dos atendimentos, reduzindo tempos de internação e de recuperação, custos e, concomitantemente, reduzindo a taxa de prestação de serviços.

\section{TELEMEDICINA}

Telemedicina compreende a oferta de serviços ligados aos cuidados com a saúde, nos casos em que a distância é um fator crítico; tais serviços são prestados por profissionais da área da saúde, usando tecnologias de informação e de comunicação para o intercâmbio de informações válidas para diagnósticos, prevenção e tratamento de doenças e a contínua educação de prestadores de serviços em saúde, assim como para fins de pesquisas e avaliações (Rede Universitária de Telemedicina, 2008).

No Brasil, as ações em telemedicina vêm sendo realizadas desde a década de 90, porém de forma tímida. Um país com dimensões continentais, no entanto, tem muito a ganhar com a formação e a consolidação de redes colaborativas integradas de assistência médica à distância. Benefícios como a redução de custos com transportes e comunicações e a possibilidade de levar a medicina especializada a regiões remotas do país mediante a consulta on-line e o telediagnóstico por imagem 
na área de atendimento são indicadas como as principais vantagens da telemedicina (Rede Universitária de Telemedicina, 2008).

\section{ATENÇÃO DOMICLLIAR}

Esta modalidade de tratamento da saúde - atendimento médico domiciliar, a possibilidade da coleta laboratorial para análises clínicas na residência do paciente, o envio de exames e acompanhamento do paciente à distância, entre outros - deverá crescer em razão do envelhecimento da população, da necessidade de humanização do atendimento, bem como da economia de recursos gerada e da redução do tempo de internação. Essa mudança forçará as empresas a buscar alternativas que resultem em equipamentos dotados de portabilidade, conectividade e segurança para que possam ser operados por não especialistas.

NOVAS TECNOLOGIAS

A par das tecnologias da informação e comunicação que já estão sendo incorporadas nos equipamentos médico-hospitalares, conforme exemplos citados e cujas tendências indicam a intensificação do processo que viabilizará a telemedicina e a atenção domiciliar, destaquem-se, entre outros, a nanotecnologia e os novos materiais como as principais perspectivas para os próximos anos.

A nanotecnologia permite trabalhar em escala quântica/atômica. Ao variar a estrutura e a composição de materiais comuns, os cientistas podem mudar dramaticamente suas propriedades físicas, químicas e biológicas. As nanopartículas podem viajar livremente pela corrente sanguínea para atacar um câncer específico, ser colocadas em um colírio para tratar de um glaucoma e produzir microdispositivos médicos capazes de tornar possíveis cirurgias atômicas (Kershner, 2007). Mostrando a interdependência e a tendência convergente do CEIS, prevê-se que medicamentos nanotecnológicos atuarão como minúsculos dispositivos guiados para a liberação progressiva do fármaco em alvos específicos e com diminuição de efeitos indesejados causados pelos fármacos (Polleto, Pohlmann \& Guterres, 2008).

Em termos de tecnologias de monitoração, por exemplo, o desenvolvimento de moléculas com capacidade de se reconhecerem mutuamente pode viabilizar novos sensores químicos e biossensores para uso em equipamentos como capinógrafos (monitoramento do dióxido de carbono), oxímetros ( para medição do nível de oxigênio) e detectores de nível de glicose e pressão sanguínea. Pelo tamanho desses sensores, será possível colocá-los dentro do paciente de forma que transmitam dados coletados em seu organismo por meio de pequenos dispositivos de comunicação eletrônica. A grande vantagem dessas tecnologias será a de disponibilizar a monitoração em tempo real de parâmetros biológicos e bioquímicos do paciente (ABDI, 2008).

$\mathrm{Na}$ área de imagens, por exemplo, prevê-se o desenvolvimento de câmeras de nanotecnologia, compostas de diversas unidades semelhantes aos olhos compostos 
dos insetos, a serem utilizadas dentro do corpo humano. Cada unidade fornecerá parte da imagem, dotada de bioluminescência. $O$ tamanho reduzido permite que as unidades vejam qualquer área do corpo humano sem necessidade de operação. Esse é um exemplo do desenvolvimento futuro da tecnologia microscópica para novos usos (Kershner, 2007).

Outra área em que se preveem grandes desenvolvimentos é a de materiais e suas tecnologias de processamento, que combinem características mecânicas, funcionais, biológicas, farmacêuticas ou mesmo terapêuticas dos materiais. Por exemplo, prevê-se o desenvolvimento de polímeros com memória para clínicas médicas - materiais se transformam em uma forma predeterminada quando ativados por luz, calor ou campo magnético e podem ser implantados e ativados em qualquer lugar no corpo humano. A primeira dessas tecnologias aparecerá na forma de autossuturas e aparelhos ortodônticos que se ajustam rapidamente.

Outra área promissora é a do desenvolvimento de pinos de titânio para osseointegração. Inicialmente utilizada em implantes odontológicos, a técnica começou a ser usada em próteses faciais e seu grande potencial de aplicação está no emprego de parafusos de titânio em próteses ortopédicas (Martins, 2008).

A intensificação das pressões para a redução dos custos dos sistemas de saúde, o qual precisa incorporar parcelas cada vez maiores da população que crescentemente se torna mais longeva, e o caráter cada vez mais preventivo da medicina, reduzindo tempos de internação e recuperação, vêm estimulando o desenvolvimento de novas tecnologias que possibilitem processos de recuperação nas próprias residências, apoiados pelo desenvolvimento da telemedicina. Nesse contexto, o incentivo a novos procedimentos clínicos minimamente invasivos e menos agressivos, a personalização do atendimento e a monitoração remota levam a potencializar a miniaturização e o desenvolvimento de dispositivos inteligentes, privilegiando a convergência entre os diferentes campos do conhecimento, como os das tecnologias da informação e comunicação, da nanotecnologia e dos novos materiais. Tal sinergia viabilizará benefícios clínicos sem precedentes (Arabe, 2003).

Assim, os principais determinantes a longo prazo dos investimentos esperados na indústria de equipamentos e materiais médico-hospitalares e odontológicos no Brasil dizem respeito às pressões por reduções de custos, à intensificação da medicina preventiva, da telemedicina e da atenção domiciliar, e à convergência tecnológica, isto é, à incorporação crescente de tecnologias da informação e comunicação, nanotecnologia, novos materiais, entre outras. O Quadro 10 sintetiza o cenário desejável a longo prazo, apresentando os determinantes da dinâmica do investimento esperado, as metas para 2022, impactos dos investimentos no segmento e os efeitos esperados no conjunto da economia.

Em um cenário a longo prazo a expectativa é de que os investimentos na indústria promovam a ampliação de sua competitividade, com adensamento tecnológico de 
seus produtos e processos e efeitos positivos em termos de sua participação no PIB, de ampliação do emprego e da renda e de redução do déficit comercial.

No que se refere à identificação de equipamentos prioritários para desenvolvimento nacional, recupera-se o exposto anteriormente, destacando-se aqueles equipamentos para os quais é preciso construir competitividade, como, por exemplo:

- chips para a indústria de equipamentos hospitalares, que podem ser utilizados em inúmeros equipamentos eletromédicos;

- hemodialisadores: filtros utilizados em hemodiálise;

- artigos e instrumentos cirúrgicos (instrumental) fabricados com plásticos de engenharia, e não pelo método tradicional de indústrias metalúrgicas;

- equipamentos para diagnóstico biológico de última geração (testes rápidos, plataformas para diversas doenças, sondas moleculares etc.);

- equipamentos para diagnóstico por imagens.

Essas apostas levam em conta tanto o perfil tecnológico e industrial atual das empresas que compõem a indústria de equipamentos e materiais médico-hospitalares e odontológicos no Brasil quanto o caráter cumulativo do aprendizado, isto é, o aspecto path dependent das trajetórias tecnológicas. Levam em consideração também que as iniciativas governamentais de apoio ao seu desenvolvimento, desenhadas a partir de agora, gerarão frutos efetivos a longo prazo. É justamente a promoção da adoção de trajetórias tecnológicas cada vez mais densas por parte das empresas que conduzirá à construção de vantagens competitivas em determinados nichos de mercado, em um futuro desejável a longo prazo. 
Quadro 10 - Perspectivas a longo prazo. Cenário desejável - 2022

\begin{tabular}{|c|c|c|c|}
\hline $\begin{array}{l}\text { DETERMINANTES DA DINÂMICA DO } \\
\text { INVESTIMENTO ESPERADO }\end{array}$ & METAS PARA 2022 & $\begin{array}{l}\text { IMPACTOS NOS INVESTIMENTOS } \\
\text { DO SEGMENTO }\end{array}$ & $\begin{array}{l}\text { EFEITOS ESPERADOS NO CONJUNTO } \\
\text { DA ECONOMIA }\end{array}$ \\
\hline $\begin{array}{l}\text { Pressões por reduções de custos. } \\
\text { Medicina preventiva. } \\
\text { Telemedicina. } \\
\text { Atenção domiciliar. } \\
\text { Novas tecnologias. } \\
\text { Consolidação da articulação } \\
\text { entre o Subsistema de Base } \\
\text { Mecânica, Eletrônica e de } \\
\text { Materiais e os serviços de saúde } \\
\text { (convergência tecnológica e de } \\
\text { mercado). }\end{array}$ & $\begin{array}{l}\text { Aumento nos gastos } \\
\text { públicos em saúde } \\
\text { para } 7 \% \text { do PIB. } \\
\text { Crescimento médio } \\
\text { do mercado brasileiro } \\
\text { de equipamentos de } \\
5 \% \text { a.a. } \\
\text { Equilíbrio competitivo } \\
\text { na balança comercial. } \\
\text { Ampliação dos gastos } \\
\text { em P\&D. } \\
\text { Desenvolvimento } \\
\text { tecnológico de } \\
\text { equipamentos e } \\
\text { materiais prioritários } \\
\text { no âmbito do SUS. }\end{array}$ & $\begin{array}{l}\text { Aumento na capacidade } \\
\text { produtiva associada com } \\
\text { aumento na escala de } \\
\text { produção e diversificação } \\
\text { em produtos de maior valor } \\
\text { agregado. } \\
\text { Desenvolvimentos } \\
\text { tecnológicos em: } \\
\text { - tecnologias mais } \\
\text { efetivas e rápidas; } \\
\text { - tecnologias que } \\
\quad \text { favoreçam o diagnóstico } \\
\text { precoce; } \\
\text { - amplo uso das TICs e de } \\
\text { equipamentos dotados } \\
\text { de conectividade; } \\
\text { • equipamentos dotados } \\
\text { de portabilidade, } \\
\text { conectividade e } \\
\text { segurança; } \\
\text { - equipamentos menos } \\
\text { invasivos e cuja tônica } \\
\text { seja a convergência } \\
\text { tecnológica. } \\
\text { Consolidação do Brasil como } \\
\text { principal polo da indústria } \\
\text { de equipamentos e materiais } \\
\text { na América Latina. } \\
\text { Fortalecimento do sistema } \\
\text { nacional de inovação } \\
\text { em saúde e sua maior } \\
\text { articulação com o sistema } \\
\text { de saúde. }\end{array}$ & $\begin{array}{l}\text { Expansão do PIB e geração de } \\
\text { emprego. } \\
\text { Modernização da capacidade } \\
\text { produtiva e aumento da } \\
\text { produtividade. } \\
\text { Desenvolvimento tecnológico e } \\
\text { industrial/capacitação inovativa } \\
\text { em equipamentos e materiais } \\
\text { estratégicos. } \\
\text { Aumento de } 1,5 \text { a } 2,0 \% \text { na } \\
\text { participação do segmento no PIB. } \\
\text { Redução no déficit na balança } \\
\text { comercial no complexo da saúde. } \\
\text { Aumento do dispêndio em P\&D } \\
\text { e com atividades inovativas do } \\
\text { setor privado. } \\
\text { Ampliação e diversificação das } \\
\text { exportações brasileiras. }\end{array}$ \\
\hline
\end{tabular}

P\&D - Pesquisa e Desenvolvimento; PIB - Produto Interno Bruto; SUS - Sistema Único de Saúde; TIC - Tecnologias da Informação e Comunicação.

Fonte: elaboração própria. 


\section{PROPOSIÇÕES DE POLÍTICAS SETORIAIS}

O Quadro 11 apresenta proposições de políticas para a indústria de equipamentos e materiais médico-hospitalares e odontológicos, as quais visam a reforçar e ampliar sua competitividade, segundo os investimentos induzidos e estratégicos.

Os investimentos induzidos teriam um papel fundamental na conformação do cenário possível, a médio prazo, ao passo que os investimentos estratégicos estariam correlacionados a transformações mais profundas no âmbito da indústria e, portanto, associados com o cenário desejável a longo prazo. No entanto, deve-se ressaltar que para que as metas a longo prazo possam ser alcançadas, todos os investimentos ligados ao cenário a médio prazo, seja no âmbito dos incentivos, seja no âmbito da regulação e coordenação, precisam ser efetivos.

Saliente-se, ainda, que algumas proposições de política aqui apresentadas aparecem tanto para o médio prazo quanto para o longo prazo, o que sugere que, dependendo do grau de intensidade, os mesmos instrumentos podem ser utilizados com foco tanto em investimentos induzidos como em estratégicos. Cada um dos grandes grupos de incentivos será sucintamente apresentado a seguir.

\section{Uso do Poder de Compra do Estado}

O Estado, por seu papel de grande consumidor de bens e serviços da indústria, pode direcionar o desenvolvimento desta, em decorrência do seu poder de compra e do estabelecimento de compras preferenciais. É importante destacar a necessidade de articulação entre diversas ações, como as encomendas tecnológicas (Cruz, 2003), o financiamento seletivo das atividades tecnológicas e industriais, políticas de comércio exterior, benefícios fiscais e a adequação do sistema regulatório. O uso do poder de compra do Estado estaria diretamente relacionado ao aumento dos gastos públicos em saúde (metas de $5 \%$ e $7 \%$ do PIB para 2012 e 2022, respectivamente), ao crescimento da indústria brasileira de equipamentos e materiais médico-hospitalares e odontológicos (metas de 3,4\% a.a. e 5\% a.a. para 2012 e 2022, respectivamente) e à redução do déficit da balança comercial (20\% para 2012 e 50\% para 2022).

\section{Financiamento e Outros Incentivos para Aquisições e Fusões e de Profissionalização da Gestão das Empresas}

Diante do contexto empresarial apresentado, deve-se estimular um certo grau de concentração na indústria de modo a alterar o seu perfil atual, em que sobressaem o alto grau de segmentação em combinação com grande número de empresas de pequeno e médio portes. Estrutura familiar e altos custos fixos intangíveis específicos deste segmento (certificações e estabelecimento de redes de representação e de assistência técnica) são fatores limitantes ao crescimento das empresas (Gutierrez \& Alexandre, 2004). Do mesmo modo, deve-se estimular a mudança de gestão familiar, característica de um grande número de empresas da indústria, para uma gestão profissional. Além disso, tendo em vista que, mundialmente, a estrutura da indústria 
comporta empresas de pequeno e médio portes, faz-se necessária a dinamização das pequenas e médias empresas exportadoras por meio da eliminação de vantagens de aquisição de produtos importados em relação aos produzidos no Brasil, de modo a se estimular a produção nacional.

\section{Financiamento do Investimento em Equipamentos e Materiais para o SUS}

Neste caso, associa-se a identificação de prioridades nacionais na implementação de estratégias de especialização com o uso do poder de compra do Estado. Conforme salientado anteriormente, a Portaria n. 978 de maio de 2008 elege um conjunto de equipamentos e materiais prioritários no âmbito do SUS como itens que devem receber apoio em termos do adensamento tecnológico envolvido e da ampliação da capacidade produtiva. Em ambos os cenários, de médio e longo prazos, aparece como meta o desenvolvimento tecnológico de produtos prioritários para o SUS. No entanto, para o cenário de longo prazo, os incentivos ao adensamento da cadeia produtiva em atividades de alta densidade tecnológica e à priorização de atividades de inovação precisam coexistir para que essa meta possa ser atingida. Deve-se estimular a criação de novos instrumentos de fomento à formação de redes entre as empresas, universidades e institutos tecnológicos que promovam sinergias no âmbito da inovação e resultem em atividades produtivas de maior valor agregado e, concomitantemente, em aumento da eficiência e melhora da competitividade das empresas da indústria. Diante da intensificação da tendência à incorporação de tecnologias oriundas de outros setores (tecnologias da informação e comunicação, eletrônica, nanotecnologia, novos materiais etc.), essas parcerias deveriam fomentar a complementaridade tecnológica mediante a participação de agentes com especializações distintas. Deve-se estimular, ainda, com crescentes investimentos em atividades de pesquisa, desenvolvimento e inovação, o pleno uso do aparato político-institucional para promover o engajamento das empresas em tais atividades. Além disso, a seletividade no âmbito dos incentivos e no nível de complexidade tecnológica deve ser critério de orientação das políticas de apoio ao desenvolvimento tecnológico e industrial. $\mathrm{O}$ apoio seletivo a projetos empresariais que associem vantagens econômicas e tecnológicas com vantagens sociais e sanitárias deve ser uma macro-orientação no âmbito do aparato políticoinstitucional de fomento tecnológico e industrial do setor produtivo.

\section{Promoção da Exportação}

A exposição a mercados externos e a adequação a requisitos de competitividade que estes impõem representam uma forma de ampliação das vantagens competitivas das empresas nacionais. Devem ser aprofundadas ações e atividades, a exemplo das desenvolvidas pela Apex/Abimo, que capacitem as empresas nacionais para realizar atividades exportadoras. Este ponto relaciona-se com a ampliação da competitividade da indústria e com a redução do déficit externo, previstos nos cenários de médio e longo prazos. 
Estímulos ao Desenvolvimento de Infraestrutura de Serviços Tecnológicos para a Qualificação de Fornecedores

Sistemas de qualificação de fornecedores representam custos para as empresas, mas, ao mesmo tempo, abrem oportunidades de acesso a conhecimento técnico, levando à melhoria dos processos de produção, estocagem, distribuição, entre outros, o que confere às empresas vantagens adicionais. Esta é uma questão de base para o sucesso de outros incentivos. $O$ desempenho competitivo da indústria é fortemente dependente dos insumos utilizados no processo de produção, o que pode ser comparado à relação entre fármacos e medicamentos. No entanto, a estrutura fragmentada da indústria de equipamentos e materiais médico-hospitalares e odontológicos não favorece a ação direta das empresas no controle da qualidade de seus insumos, sendo necessária a interferência de instituições governamentais para auxiliar nesse processo. Todo o desenvolvimento de novos produtos e o adensamento tecnológico passam pelo desenvolvimento de infraestrutura de serviços tecnológicos para qualificação de fornecedores, com impacto direto sobre as metas a médio e longo prazos.

\section{Estímulo ao Desenvolvimento de Arranjos de Inovação}

Sugere-se a articulação de grandes redes de assistência com a indústria de equipamentos para a conformação de arranjos de inovação. Instituições como o Instituto Nacional do Câncer, o Instituto Nacional de Traumatologia e Ortopedia e o Instituto Nacional de Cardiologia, centros de referência nacionais na sua especialidade e grandes demandantes da indústria de equipamentos e materiais médico-hospitalares e odontológicos, poderiam se constituir em polos líderes dinâmicos, em articulação com empresas, de promoção da inovação. Do mesmo modo, a forte concentração geográfica das empresas da indústria é fator facilitador do desenvolvimento de arranjos de inovação: a geração de externalidades positivas oriundas dessa proximidade favorece a elevação da produtividade das empresas. A proximidade geográfica pode, inclusive, ser fator positivo no que se refere à possível concentração de empresas.

A regulação deve ser vista como um fator estratégico que condiciona fortemente a ampliação da competitividade das empresas e o desenvolvimento do subsistema no Brasil. É crucial a adoção de abordagens proativas que possibilitem a adequação das empresas, ao mesmo tempo que estimulem a criação de um ambiente regulatório que associe qualidade com inovação. $\mathrm{O}$ atendimento a normas e regulamentos que dispõem sobre segurança, desempenho, instalação e uso desses equipamentos de todos os fabricantes nacionais, embora signifique custos, representa também o atendimento de padrões de qualidade na defesa e proteção do consumidor e, sobretudo, oportunidades econômicas e competitivas. Deve-se estimular o pleno uso do aparato regulatório da Agência Nacional de Vigilância Sanitária (Anvisa), incentivando as empresas a adotarem o registro de produtos e de boas práticas de fabricação, bem como sistemas de fiscalização mais categóricos. Um papel mais atuante do Instituto Nacional de Metrologia, Normalização e Qualidade Industrial (Inmetro), com a ampliação de produtos contemplados nos esforços de avaliação de conformidade e de metrologia, é absolutamente desejável. 
No âmbito da coordenação, destaca-se, inicialmente, a necessidade de articulação efetiva entre as agências reguladoras (Anvisa e Inmetro) e as demandas empresariais que compatibilize qualidade e competitividade, envolvendo o sistema de ciência e tecnologia e órgãos de fomento como o BNDES e a Finep, e operacionalize um quadro regulatório favorável, ágil e eficiente, indutor da qualidade e da inovação.

Talvez o maior desafio para as perspectivas apresentadas, que exigem elevada articulação sistêmica, vincula-se ao pleno uso de fóruns políticos e setoriais, que permita a interação de todos os agentes direta ou indiretamente envolvidos com a indústria de equipamentos e materiais médico-hospitalares e odontológicos. O Subsistema de Base Mecânica, Eletrônica e de Materiais passou a constituir prioridade dos grandes programas nacionais de desenvolvimento, como a Política de Desenvolvimento Produtivo (Brasil. Ministério do Desenvolvimento, Indústria e Comércio Exterior, 2008), o Mais Saúde (Brasil. Ministério da Saúde, 2007) e o PAC da Inovação (Brasil. Ministério da Ciência e Tecnologia e Inovação, 2007). Tais programas ampliaram o foco mais tradicional na área de fármacos e medicamentos, como previsto na antiga Política Industrial, Tecnológica e de Comércio Exterior, PITCE (BRASIL. Ministério do Desenvolvimento, Indústria e Comércio Exterior, 2003), para incorporar este subsistema no contexto da prioridade que passou a ser conferida ao CEIS.

Assim como no Subsistema de Base Química e Biotecnológica, o grande marco da coordenação das ações da saúde e para o desenvolvimento industrial foi a instituição do Grupo Executivo do Complexo Industrial da Saúde (Gecis), em maio de 2008. O Gecis foi instituído para articular as ações com foco sistêmico, contemplando de modo inédito o Subsistema de Equipamentos e Materiais Médicos e envolvendo um amplo conjunto de ministérios e agências governamentais e um fórum de articulação com a sociedade em que o segmento empresarial está representado e participa dos debates e decisões.

o movimento por uma abordagem sistêmica da saúde e seu impacto nos segmentos de equipamentos e materiais já se expressam concretamente. Está em curso uma série de ações voltadas para o desenvolvimento do Subsistema de Base Mecânica, Eletrônica e de Materiais, tais como a ampliação do escopo do Profarma/BNDES, em 2007; a prioridade conferida a tais ações pelos programas de CT\&I; a transformação do escopo das ações da política de saúde e o esforço de mobilizar o aparato regulatório para o desenvolvimento empresarial em seu âmbito.

É essencial que essa coordenação resulte em convergência das diversas políticas para a indústria e conduza ao atendimento dos seus objetivos estratégicos para o reforço e ampliação de vantagens competitivas. Somente com a perspectiva de superar a fragmentação das políticas assistenciais, de produção industrial e de inovação envolvendo os ministérios da Saúde, da Ciência e Tecnologia, do Desenvolvimento, Indústria e Comércio Exterior, a Agência Brasileira de Desenvolvimento Industrial (ABDI), a Finep, o BNDES, o Inmetro, a Anvisa e associações empresariais como a Abimo, entre outros - se poderá viabilizar e potencializar a mudança de patamar pretendida para os produtos de maior densidade de conhecimento e inovação, alterando as fontes de competitividade deste subsistema. 


\section{Quadro 11 - Proposição de políticas. Síntese}

\begin{tabular}{|c|c|c|c|c|}
\hline \multicolumn{5}{|c|}{ INSTRUMENTOS } \\
\hline \multirow{3}{*}{ 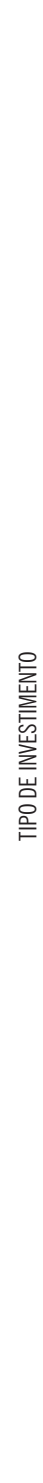 } & & INCENTIVOS & REGULAÇÃO & COORDENAÇÃO \\
\hline & INDUZIDO & $\begin{array}{l}\text { Uso do poder de compra do Estado } \\
\text { para expansão da capacidade } \\
\text { produtiva dos segmentos mais } \\
\text { intensivos em tecnologia. } \\
\text { Financiamento e outros } \\
\text { incentivos para aquisições e } \\
\text { fusões e de profissionalização da } \\
\text { gestão das empresas. } \\
\text { Financiamento do investimento } \\
\text { e incentivos tributários para a } \\
\text { produção de equipamentos e } \\
\text { materiais prioritários para o SUS. } \\
\text { Promoção da exportação. } \\
\text { Estímulos ao desenvolvimento } \\
\text { da infraestrutura de serviços } \\
\text { tecnológicos para qualificação de } \\
\text { fornecedores. }\end{array}$ & $\begin{array}{l}\text { Ação prioritária das agências } \\
\text { de regulação para promoção } \\
\text { e difusão de padrões de } \\
\text { qualidade da produção nacional } \\
\text { simultaneamente à garantia } \\
\text { de segurança e eficácia dos } \\
\text { produtos em saúde. }\end{array}$ & $\begin{array}{l}\text { Consolidação e fortalecimento } \\
\text { do Gecis como instância de } \\
\text { articulação da política industrial, } \\
\text { de CT\&l e de saúde para } \\
\text { promover a capacidade produtiva } \\
\text { e de inovação incremental. } \\
\text { Harmonização do sistema } \\
\text { de coordenação regulatória } \\
\text { articulando competitividade } \\
\text { e proteção à saúde, com } \\
\text { articulação nas instâncias de } \\
\text { regulação sanitária. }\end{array}$ \\
\hline & ESTRATÉGICO & $\begin{array}{l}\text { Uso estratégico do poder de } \\
\text { compra do Estado para a } \\
\text { transformação da estrutura } \\
\text { produtiva e para a inovaçãa } \\
\text { incremental e radical. } \\
\text { Financiamento e incentivos para } \\
\text { segmentos que sejam estratégicos } \\
\text { para as condições futuras de } \\
\text { saúde e para a inovação. } \\
\text { Estímulo ao desenvolvimento } \\
\text { de arranjos produtivos para a } \\
\text { inovação, articulado com os } \\
\text { demais subsistemas. } \\
\text { Estímulo ao adensamento da } \\
\text { cadeia produtiva em atividades } \\
\text { de alta densidade tecnológica } \\
\text { (eletrônica, novos materiais etc.). } \\
\text { Priorização de atividades de } \\
\text { inovação para todos os tipos de } \\
\text { incentivos financeiros e fiscais. }\end{array}$ & $\begin{array}{l}\text { Criação de um ambiente } \\
\text { regulatório que associe qualidade } \\
\text { com inovação (Lei da Inovação). } \\
\text { Interação das instituições de C\&T } \\
\text { operacionalizando concretamente } \\
\text { um novo quadro regulatório para } \\
\text { as inovações com impacto efetivo } \\
\text { na assistência à saúde. }\end{array}$ & $\begin{array}{l}\text { Consolidação, fortalecimento e } \\
\text { ampliação do poder decisório } \\
\text { do Gecis como instância } \\
\text { de articulação da política } \\
\text { industrial, de CT\&l e de saúde } \\
\text { para promover a capacidade } \\
\text { produtiva, a inovação } \\
\text { incremental e radical. } \\
\text { Harmonização do sistema } \\
\text { de coordenação regulatória } \\
\text { articulando competitividade e } \\
\text { proteção à saúde com foco na } \\
\text { inovação. }\end{array}$ \\
\hline
\end{tabular}

C\&T - Ciência e Tecnologia; CT\&I - Ciência, Tecnologia e Inovação; Gecis - Grupo Executivo do Complexo Industrial da Saúde; SUS - Sistema Único de Saúde.

Fonte: elaboração própria. 